\title{
DEBERES DE NO DISCRIMINAR EN EL DERECHO PRIVADO
}

\section{NON-DISCRIMINATION DUTIES IN PRIVATE LAW}

Felipe Chahuán*

Beltrán Flores*

\section{RESUMEN}

Los compromisos políticos que combaten la discriminación plantean la pregunta por la medida en que las personas resultan obligadas en sus relaciones privadas. El punto es complejo, porque en el injusto conviven consideraciones individuales y colectivas cuya compatibilidad con la autonomía privada se presenta de manera muy distinta. El lugar de los deberes de no discriminar en el derecho privado puede aclararse si entendemos que el encuentro entre lo que hay de individual y de colectivo en ellos no se produce al aplicar las reglas, sino al instaurarlas. Formulada esta idea, este trabajo reflexiona sobre los encuentros y desencuentros entre los compromisos contrarios a la discriminación y el derecho privado patrimonial, proponiendo alternativas y despejando dudas que podrían ser relevantes en el proceso constituyente que en Chile se acaba de iniciar.

PALABRAS CLAVE: Discriminación; igualdad; derecho privado; derechos constitucionales; constitucionalización del derecho privado.

\section{ABSTRACT}

Political commitments against discrimination pose the question to what extent individuals should be bound by them. This dilemma is challenging

* Magister Juris, University of Oxford. Instructor del Departamento de Derecho Privado, Facultad de Derecho, Universidad de Chile. Dirección postal Pío Nono 1, Providencia, Región Metropolitana. Correo electrónico: lchahuan@derecho.uchile.cl

** Licenciado en Ciencias Jurídicas y Sociales, Universidad de Chile. Ayudante adhonorem de los departamentos de Ciencias del Derecho y Derecho Privado, Facultad de Derecho, Universidad de Chile. Pío Nono 1, Providencia, Región Metropolitana. Correo electrónico: beltran.flores@ug.uchile.cl

Recepción: 2021-06-01; aceptación: 2021-08-04. 
since the wrong combine individual and collective dimensions which compatibility with private autonomy may emerge in different ways. The place of duties not to discriminate within private law may be clarified if we understand that the meeting between what is individual and collective about them does not occur in their application to particular cases, but in their establishment. Once this point is made clear, this work reflects on the tensions between the commitments against discrimination and private law, proposing alternatives and clearing up doubts that could be relevant in the constituent process recently initiated in Chile.

Keywords: Discrimination; Private Law; Constitutional Rights; Constitutionalization of Private Law; Horizontal Effect.

\section{INTRODUCCIÓN}

Las reglas que prohíben discriminar han sido una de las victorias del movimiento por los derechos civiles. La Constitución de 1980 prohíbe "a la ley" y a la "autoridad" establecer "diferencias arbitrarias", pero no contiene una cláusula general que obligue al Estado a combatir estas conductas ${ }^{1}$. Desde 2012 entró en vigencia una ley que prohíbe, tanto al Estado como a particulares ${ }^{2}$, discriminar arbitrariamente, sin que esta prohibición esté delimitada a algún ámbito particular -como suele estarlo en otras normas constitucionales y legales que ya estaban vigentes ${ }^{3}{ }^{3}$.

Un aspecto difícil de definir es la medida en que el establecimiento de estos deberes nos vincula en los distintos niveles en que interactuamos. La ley chilena poco ayuda a definirlo. Bajo la legislación actual, esta cuestión exige determinar si acaso la discriminación es arbitraria. En principio, así se consideran las distinciones cuyo motivo es alguna de las propiedades que la ley menciona ${ }^{4}$. Pero a diferencia de lo que ocurre en otras jurisdicciones, por muy sospechosas que parezcan las distinciones, todas pueden justificarse en el ejercicio legítimo de algún derecho fundamental. La ley menciona, en especial, aquellos derechos que demarcan nuestra privacidad y libertades personales, pero no da criterios que permitan determinar bajo qué circunstancias el ejercicio de estos derechos civiles

${ }^{1}$ Art. 2 de la Constitución Política de la República.

${ }^{2}$ Ley n. ${ }^{\circ} 20609$, de 2012.

${ }^{3}$ Véase art. 19 n. ${ }^{\text {s }} 16$ y 22 de la Constitución Política de la República (no discriminación en la elección del trabajo y en el trato del Estado y sus organismos en materia económica); art. 2 del Código del Trabajo (no discriminación en las relaciones laborales); art. 13 de la Ley n. ${ }^{\circ}$ 19496, de 1997 (prohibición de los proveedores de negar en forma injustificada la venta de bienes o prestación de servicios).

${ }^{4}$ Art. 2 de la Ley n. ${ }^{\circ} 20609$. 
es legítimo o ilegítimo ${ }^{5}$. En este contexto, los debates constitucionales podrían ser significativos.

Si la discriminación arbitraria comienza donde termina el ejercicio legítimo de nuestras libertades, nos parece que tiene valor analizar esta pregunta desde la perspectiva del derecho privado. La idea de que este orden jurídico se diferencia del derecho público adquirió su forma en torno a reglas que reconocen a los individuos una provincia en que pueden decidir con autonomía. En esto consistió el clásico sistema de derecho romano actual que propuso Friedrich von Savigny:

"La determinación por una regla jurídica consiste en que se indica a la voluntad individual un campo en el cual reina con independencia de toda voluntad ajena"6 (traducción libre).

Este tipo de reglas, aunque no agotan el contenido del derecho privado, le confieren su fuerza normativa. La legislación antidiscriminación, entonces, representa un desafío al derecho privado, que nos convoca a pensar en torno a las fronteras y contenidos de ambos órdenes. Se trata de una discusión de relevancia constitucional porque tanto las reglas antidiscriminación como las reglas de autonomía del derecho privado tienen un grado de protección en garantías constitucionales.

Este texto es una reflexión sobre el lugar que ocupan los deberes de no discriminación vis à vis en el derecho privado patrimonial. En la cultura jurídica chilena, el vínculo entre estos deberes y derecho privado se ha examinado, sobre todo, en materia de personas y derecho familia. En

${ }^{5}$ Véase DíAZ de VAldés (2013), p. 280 y ss.; DíAZ de VAldés (2014), pp. 167 y 175 (criticando la jerarquización de derechos fundamentales que abre la posibilidad de una justificación indeterminada de las conductas discriminatorias en el ejercicio legítimo de un derecho fundamental, e indicando la eventual inconstitucionalidad de esta solución en la ley chilena). En un sentido similar, DíAz (2013), pp. 652-658 (con referencia a los avances del derecho internacional de los derechos humanos y su contraste con la solución chilena). En relación con las formas más diferenciadas de delimitación utilizadas en el derecho comparado, un completo estudio sobre legislaciones antidiscriminación en la tradición del derecho civil puede consultarse en Havelková \& Möschel (2020), passim. Es llamativo que incluso la jurisprudencia de los tribunales internacionales, que necesariamente se produce en un plano argumentativo más general, ha pasado del análisis genérico de proporcionalidad al reconocimiento de categorías especiales protegidas y deberes derivados de las circunstancias particulares en que se produce cada acto discriminatorio; véanse, por ejemplo, los casos Comunidad Indígena Xákmok Kásek con Paraguay (2010); A. y niñas con Chile (2012); G. y otros con Ecuador (2015), decididos por la Corte Interamericana de Derechos Humanos; y los casos A., C. y B. con Reino Unido (1985); Chipre con Turquía (2001) y N. y otros con Bulgaria (2005), como ejemplo de lo mismo en la jurisprudencia del Tribunal Europeo de Derechos Humanos.

${ }^{6}$ SAVigny (1979), p. 271. 
cambio, creemos que todavía queda mucho por examinar y construir en las relaciones privadas de carácter patrimonial.

El texto lo hemos estructurado en tres secciones. Primero nos centramos en la discriminación: ¿Qué mal cometemos cuando discriminamos? Nuestro propósito es mostrar que la relación entre el injusto de discriminar y el derecho privado en gran medida depende de los fundamentos del primero y la forma en que se construye. No es tan claro en qué medida este injusto está constituido por una ofensa individual, un problema más general de distribución o ambos. Al cerrar este capítulo mostraremos que, al menos en la instauración de los deberes de no discriminar, una mirada colectiva que fije una política antidiscriminación es inexorable.

La segunda cuestión, por contrapartida, se centra en el derecho privado y sus tensiones con compromisos políticos más generales de una sociedad, como es la antidiscriminación. Advertimos que no adoptamos una tesis fuerte sobre aquello que sería constitutivo o esencial en el derecho privado para tratarlo como un sistema cerrado de reglas. No es que se trate de una pregunta que no nos interese, pero creemos que no es necesario asumir un concepto unívoco para los propósitos de este texto. Nuestras referencias al derecho privado aluden a las reglas que consideramos paradigmáticas o centrales de este orden. El objetivo de esta sección es revisar distintos 220 mecanismos y formas por las que el derecho privado participa de compromisos políticos, en particular, de la protección de derechos constitucionales.

Por último, en la tercera sección nos enfocamos en cómo el derecho privado puede internalizar distintos deberes que podrían surgir de una agenda constitucional antidiscriminación. Examinamos, además, si su imposición a particulares supone abolir reglas paradigmáticas de derecho privado patrimonial. Nuestra conclusión es que no, en la medida que se trate de deberes ex ante definidos que complementen, pero no subordinen al derecho privado.

\section{DOS CASOS DE DISCRIMINACIÓN}

A inicios de la década de 1990, la Corte de Apelaciones de Santiago condenó a un club privado a pagar una multa por impedir la entrada a una mujer coreana ${ }^{7}$. El club, acusado de discriminación, intentó justificar su decisión en la molestia que causaba a otros usuarios el mal olor que atribuían a los supuestos hábitos alimentarios de la cultura a los que la mujer pertenecía; sin embargo, esta defensa fue desestimada.

\footnotetext{
${ }^{7}$ Servicio Nacional del Consumidor con Centro de Salud y Recreación Gunter Mund y Compañía Limitada (1993).
} 
En otro caso, resuelto más de veinte años después, la Corte Suprema consideró que una academia de teatro discriminó a un estudiante con discapacidad por no adaptar las exigencias de aprobación de un curso de expresión corporal a sus especiales necesidades ${ }^{8}$. El conflicto comenzó cuando la academia se retractó de su determinación anterior de admitir al estudiante, anticipando que su condición motora le impediría cumplir con los requisitos para aprobar algunos de los cursos que formaban parte del programa. Después de una primera demanda del estudiante afectado, la academia se comprometió a reincorporarlo en forma gratuita. El segundo semestre del año en que fue reincorporado, sin embargo, la academia le comunicó que no podría continuar sus estudios al haber reprobado el curso de expresión corporal. El estudiante nuevamente interpuso una acción fundada en el deber de no discriminar. Contra esta segunda acción, la academia centró su defensa en que su libertad de enseñanza le permitía fijar de manera autónoma sus criterios de evaluación académica. La Corte Suprema rechazó este argumento al considerar que la libertad de enseñanza no podía justificar un trato discriminatorio. La academia tenía el deber de adaptar sus evaluaciones a las necesidades de los estudiantes con discapacidad que hubiesen sido aceptados.

Ambos casos fueron calificados jurídicamente como instancias de discriminación. Pero ċson reprochables de la misma manera? En el primer caso, la Corte de Apelaciones de Santiago consideró que la mujer había sido discriminada porque la decisión del club privado atentaba contra la dignidad que la Constitución y los tratados internacionales ratificados por Chile reconocían a todas las personas por igual. Además, el centro había infringido la prohibición de negar de forma injustificada la prestación de servicios prevista en la antigua legislación de consumidores, en una disposición similar a la incluida en la ley actualmente vigente ${ }^{9}$.

En el segundo caso, la Corte Suprema también invocó la dignidad e igualdad ante la ley consagradas en la Constitución y los tratados internacionales, pero la razón que fue determinante para aceptar la demanda del estudiante fue la igualdad de oportunidades que la ley consagra a favor de las personas con discapacidad. Dos circunstancias adicionales fueron relevantes para que la Corte asignara a la academia el deber de adaptar su metodología de evaluación a las necesidades del estudiante: primero, que estos "ajustes no serían en este caso una carga desproporcionada para

${ }^{8}$ U. con Fernando González Mardones y Compañía Limitada (2019).

${ }^{9}$ Art. 13 de la Ley n. ${ }^{\circ}$ 19496. Sobre la vinculación entre no discriminación, igualdad y dignidad, véanse los avances de la jurisprudencia internacional en sede de derechos humanos; por ejemplo, en el ámbito latinoamericano, A. y niñas con Chile (2012), párrafo 79; N. y otros (dirigentes, miembros y activista del Pueblo Indígena Mapuche) con Chile (2014), párrafo 197; E. con Perú (2014), párrafo 216, entre otros. 
la demandada" y, segundo, que el estudiante había sido voluntariamente aceptado a cursar el taller ofrecido.

Cada uno de estos casos puede reflejar concepciones distintas sobre la discriminación (no incompatibles entre sí, pero distintas). Aunque igualdad y no discriminación suelen ponerse una al lado de otra ${ }^{10}$, su vinculación puede ser planteada de maneras muy diferentes (algunas débiles, otras más fuertes). No hablamos de lo mismo si lo que reprochamos es la negación del igual estatus moral de la persona afectada o si, en verdad, lo que nos molesta es privar a la víctima de algo con que todas y todos debiésemos contar por igual (sean libertades, oportunidades o condiciones materiales, según qué tan liberales o igualitarios seamos) ${ }^{11}$. Este contraste se ha planteado como una diferencia entre igualdad formal e igualdad sustantiva. La primera constituiría un principio deontológico que depende del valor o desvalor de nuestras acciones -no de sus consecuencias-; la segunda, en cambio, correspondería a un principio teleológico cuya realización se mide por el logro de fines ${ }^{12}$.

Al condenar al club privado por discriminación, la Corte de Apelaciones de Santiago no indagó si la demandante podía asociarse a otros clubes o si pertenecía a un grupo que enfrentaba mayores desventajas que de otros. Lo que en verdad parece haber importado no fue la privación de una libertad ni de un bien, sino el solo hecho de someter a la mujer coreana a un trato distinto en razón de su pertenencia étnica. De este modo, una regla 'separadas pero iguales' (por ejemplo, creando salas especiales para socias coreanas) no habría solucionado el problema ${ }^{13}$. El injusto se configuró porque las diferencias de trato raciales degradan a las personas ${ }^{14}$.

Acusar al club de degradar a una persona, podría decirse, es una lectura errada de sus intenciones. Las empresas, en general, no se dan la libertad de actuar de este modo, porque su fin es maximizar utilidades ${ }^{15}$.

${ }^{10}$ Expresivo de ello es que los deberes de no discriminación estén recogidos en cláusulas o legislaciones de igualdad. Por ejemplo, art. 19 n. ${ }^{\circ} 2$ de la Constitución Política de la República; art. 24 de la Convención Americana sobre Derechos Humanos. Las discusiones filosóficas y jurídicas sobre la discriminación también hacen lo mismo, véase FrEDMAN (2011), en especial pp. 1-37; Comisión Inter-Americana de Derechos Humanos (2019), pp. 18-22 y, con referencia a las reglas de prueba en casos por discriminación, MONAHAN et al. (2008), p. 1742 y ss. Contra esta tendencia, Holmes (2005), passim.

${ }^{11}$ Una obra que reúne distintas concepciones sobre los fundamentos de la discriminación, en Hellman \& Moreau (2014).

${ }^{12}$ Holmes (2005), pp. 177-182; Foran (2019), p. 917.

${ }^{13}$ Nos referimos a una regla como la que conoció la Corte Suprema estadounidense en B. v. Board of Education (1954).

${ }^{14}$ Hellmann (2008), pp. 29-32 (considerando que el injusto de discriminar está en la degradación, esto es, en tratar a alguien como si tuviese un valor moral inferior).

${ }^{15}$ Incluso, se ha argumentado que, en la medida que excluye a personas que pueden resultar eficientes y además implica costos por hacerlo, la discriminación sería costosa para 
Todas y todos valen nada más y nada menos que el precio que pagan ${ }^{16}$. Lo único que buscaba el club era evitar la huida de los socios molestos; jamás juzgar si la etnia de la mujer era mejor o peor que la del resto. ¿Por qué, entonces, obligarlo a asumir los costos de un problema que no le es atribuible?

Pocas veces quien discrimina tiene la intención de degradar. Es más frecuente que la diferencia de trato se explique por ciertas características que se asocian a alguna propiedad de una persona, o sea, por un prejuicio ("no tengo nada contra los coreanos, pero sus hábitos alimentarios producen que su cuerpo expela mal olor"). Incluso, puede que la diferencia de trato no se implemente por una convicción propia del discriminador, sino que se derive de las convicciones de otros ("no me parece mal que las parejas homosexuales adopten, pero considero que es mejor no permitirlo para evitar que nuestra sociedad homofóbica cause un daño al adoptado").

Lo que configura la discriminación no son los motivos de quien la ejerce (ni sus prejuicios $)^{17}$, sino la degradación sufrida por la víctima a causa de la razón por la que es tratada de manera diferente, con independencia de que tal razón sea compartida por quien la implemente. Por lo tanto, el club no puede defenderse argumentando que la expulsión de la mujer no fue intencionada, sino solo un efecto colateral de la discriminación del resto.

Volvamos ahora al segundo caso. Sabemos que en esa situación la Corte Suprema también reconoció un acto discriminatorio. Con todo, las razones parecen haber sido muy distintas. La falta de la academia no consistió en tratar distinto al estudiante con discapacidad; por el contrario, consistió en tratarlo igual que al resto, sin atender a sus desventajas comparativas. La única manera de conferirle la misma oportunidad que a los demás era aplicando una modalidad distinta de evaluaciones. Acciones de este tipo, por lo común llamadas acciones afirmativas, son necesarias para

las empresas. Véase BuRns (2012), pp. 1-5 y, con referencias a un estudio que mostró que las empresas más inclusivas obtienen mejores resultados, la opinión de Worstall (2016).

${ }^{16}$ La Corte Europea de Justicia conoció un caso en que una compañía belga fue acusada de discriminación luego de que uno de sus directores declarara en público que no contratarían a trabajadores inmigrantes porque ello incomodaba a sus clientes. La compañía se excusó argumentando que jamás se había actuado con la intención de discriminar, sino solo para cumplir con las exigencias de los clientes y evitar empeorar su situación de mercado. Centrum voor gelijkheid v. F., ECJ C-54/07.

${ }^{17}$ Hellman (2008), pp. 24-25; 91-92; Gardner (2018), pp. 9-10. Con todo, hay quienes han calificado a la discriminación directa como una forma intencional o basada en prejuicios. En este sentido, que parece incorrecto por lo dicho en el cuerpo del texto, WALDRON (1985), pp. 94-95. La irrelevancia de los motivos o intenciones ha sido también reconocida por la jurisprudencia internacional en sede de derechos humanos; por ejemplo, en el ámbito americano, en los casos N. y otros con República Dominicana (2012), párrafo 234, y A. M. y otros ("Fecundación in vitro") con Costa Rica (2012), párrafo 286. 
que algunos rasgos, como en este caso la discapacidad, no se traduzcan en una desventaja ${ }^{18}$. Aunque la carga suponía que la academia soportara un costo, como ya dijimos, la Corte consideró que se trataba de una carga soportable en la medida que no resultaba "desproporcionada" (sin dar ningún antecedente sobre su valor) y, sobre todo, porque había sido la misma academia la que había aceptado al alumno. De este modo, la carga se insertaba en una relación contractual que, al menos en principio, había sido libremente consentida por la academia.

Esta última consideración hace pensar que el resultado del juicio hubiese sido distinto si el contrato no se hubiese celebrado. Pero, incluso en este caso, podemos reconocer un problema en que la razón tras el rechazo fuese la imposibilidad del estudiante de cumplir los requisitos normales de admisión. Es probable que estos requisitos dejasen fuera a todas o a una gran parte de estudiantes con discapacidad, en comparación a otros estudiantes no afectados por el mismo impedimento. La academia, entonces, no estaría basando su decisión de manera directa en la discapacidad del estudiante, pero en la práctica su decisión indirectamente tendría el mismo impacto que si lo hiciera ${ }^{19}$.

Desde la década de $1970^{20}$, es usual que las legislaciones y el derecho internacional de los derechos humanos prohíban la discriminación indirecta, 224 pero, a diferencia de lo que ocurre con la directa, no lo hagan bajo toda circunstancia ${ }^{21}$. El trato que colateralmente resulta adverso para personas que pertenecen a algún grupo es permitido si logra ser justificado por alguna razón a la que la ley confiere protección ${ }^{22}$. Podría ser, por ejemplo, la libertad de enseñanza de la academia, que le reconoce autonomía para decidir las habilidades exigibles a sus estudiantes.

Aunque existe consenso en que junto con la discriminación directa también debiese prohibirse la indirecta -o de impactos-, no hay acuerdo

${ }^{18}$ En Chile, Ley n. ${ }^{\circ} 20422$, de 2010, cuyo objetivo es "asegurar el derecho a la igualdad de oportunidades de las personas con discapacidad, con el fin de obtener su plena inclusión social, asegurando el disfrute de sus derechos y eliminando cualquier forma de discriminación fundada en la discapacidad" (art. 2). El título IV párrafo $10^{\circ}$ de esta ley contempla distintas acciones afirmativas, a cargo de agentes públicos y privados, que persiguen dar igual oportunidades a personas con alguna discapacidad.

${ }^{19}$ Lippert-Rasmussen (2013), pp. 55-56; Fredman (2011), p. 154.

${ }^{20} \mathrm{El}$ precedente fundacional en Estados Unidos es G. v. Duke Power Co. (1971).

${ }^{21}$ Collins \& Khaitan (2018), pp. 2-4 (con referencia a la definición de discriminación indirecta en la regulación de la Unión Europea y la Equality Act 2010 del Reino Unido). En relación con la prohibición de este tipo de discriminación de acuerdo con instrumentos y decisiones de derecho internacional, véase Corte Interamericana De Derechos Humanos (2019), pp. 30-32.

${ }^{22}$ La ley chilena, en cambio, parece dar lugar a la justificación en toda circunstancia, sin distinguir entre discriminación directa e indirecta (art. 2 de la Ley n. ${ }^{\circ}$ 20609). 
sobre sus diferencias. Una forma de verlo es que mientras la primera se enfoca en la ofensa individual, la segunda, además, persigue evitar el daño que sufren otras personas que comparten la misma característica que el afectado $^{23}$. Desde esta perspectiva, el sentido de impedir la discriminación indirecta, entonces, incluiría corregir las desventajas relativas que, desde una perspectiva colectiva enfrenta un grupo en comparación con otras personas no pertenecientes al mismo grupo. Se trataría de un propósito similar al de las acciones afirmativas, pero configurado a través de un deber distinto (una prohibición, en vez de la exigencia de dar facilidades) ${ }^{24}$.

Las dimensiones colectivas e individuales que puede tener una conducta discriminatoria muchas veces son consideradas en conjunto. La Corte Suprema afirmó la obligación de un colegio de permitir la asistencia a una estudiante transexual a la que se había negado acceso al establecimiento por vestir el uniforme con que las autoridades escolares identificaban el género femenino ${ }^{25}$. La decisión del colegio negaba a la estudiante autonomía para definir su identidad de género frente a la comunidad escolar. Al decidir, la Corte Suprema invocó, por una parte, "el derecho de todo individuo de auto determinar su orientación sexual" (aunque el caso, en verdad, se trataba de identidad de género); por otra parte, tuvo presente impactos más generales relativos a las obligaciones de acceso, integración e inclusión a las que están sujetos los distintos actores del sistema educacional. A diferencia del análisis de la Corte de Apelaciones de Santiago en el caso del club privado, acá sí se consideró que la decisión del colegio podía redundar en la privación de un bien.

Pero las dimensiones colectivas e individuales asociadas a la discriminación también pueden entrar en conflicto. Así lo muestra la comentada sentencia B. de la Corte Suprema estadounidense ${ }^{26}$. Un postulante blanco no admitido en el programa de medicina de la Universidad de California en Davis acusó discriminación racial, porque no pudo demostrarse que sus calificaciones académicas fuesen peores que las de otras personas sí admitidas. Ellas habrían ingresado a la universidad mediante un programa afirmativo que reservaba cupos para estudiantes que pertenecían a ciertos grupos étnicos a través de un sistema de cuotas. En una opinión dividida,

${ }^{23}$ Collins \& Khattan (2018), p. 29; Hellman (2013), p. 55; Fiss (1976), p. 124; Fredman (2018), p. 47. Contra esta posición, Foran (2019), passim.

${ }^{24}$ Sobre la relación entre acciones afirmativas y discriminación indirecta, véase Khaitan \& STEel (2018), p. 197 para quienes la discriminación indirecta está a medio camino entre un injusto de carácter público y privado, compartiendo caracteres de ambos.

${ }^{25}$ C. con Corporación Iglesia Adventista Del séptimo Día (2020).

${ }^{26}$ Regents of the University of California v. B. (1978). Un lúcido comentario sobre el caso en DwORKin (1977) y, en el contexto de un análisis de la relevancia de las decisiones jurisdiccionales en cuestiones constitucionales, DwORKIN (1986), pp. 393-397. 
el voto decisivo de la Corte Suprema sostuvo que el interés legítimo de las universidades por la diversidad justificaba considerar criterios como los del programa para seleccionar a sus estudiantes, pero que estos no podían ser el único factor de decisión. Sin perjuicio de que se tratare de una medida a favor de personas desaventajadas, "preferir miembros de cualquier grupo no por otra razón que su raza u origen étnico es discriminación en sí misma", y debía juzgarse tan estrictamente como la discriminación en contra de esas mismas minorías.

Es paradójico que la Corte Suprema estadounidense haya calificado de discriminatorio un programa que perseguía la inclusión social de personas que en los hechos eran (y siguen siendo) las más afectadas por discriminación. Aunque el programa se basara solo en criterios raciales, esas diferencias se justificaban porque la misma historia estadounidense hizo que la vida de ciertas personas estuviese marcada por su identificación con un grupo racial. Un conspirador podría pensar que solo en una sociedad profundamente discriminatoria los instrumentos legales antidiscriminación pueden terminar siendo usados contra las discriminadas ${ }^{27}$.

Lo que produce esta paradoja es la contraposición entre lo colectivo y lo individual de la discriminación. Como hemos dicho, hay quienes creen que la legislación antidiscriminación recoge tanto consideraciones indivi226 duales (sobre todo, mediante la noción de discriminación directa) como colectivas (principalmente, bajo la noción de discriminación indirecta y las acciones afirmativas $)^{28}$. Por el contrario, hay quienes ven en ella solo una de estas dimensiones $-\mathrm{O}$, al menos, le dan a alguna de ellas prioridad ${ }^{29}$.

El punto no es menor. Si la discriminación está constituida por una ofensa individual, B. puede estar en lo correcto; pero si la discriminación se mide ante todo en el acceso grupal, mirarlo como víctima pierde todo sentido. Dicho de otro modo, la calificación de una medida como discriminatoria depende de si el deber de no discriminar primeramente está asociado a un daño individual o si entendemos que se trata de deberes en beneficio de personas indeterminadas de algún grupo, sin que sea necesario que alguien en particular sea titular del derecho correlativo a no ser discriminado ${ }^{30}$. No es que desde esta segunda perspectiva los derechos individuales no tengan cabida, pero el sentido de su consagración

${ }^{27}$ Referencia a los impactos inmediatos de la decisión B. en las políticas de acceso universitario en Estados Unidos, en Posner (1979).

${ }^{28}$ Comprometidos con esta idea, Khaitan \& Steel (2018).

${ }^{29}$ Negando que la discriminación indirecta tenga fundamento en consideraciones de “daño colectivo”, Foran (2019), p. 901.

${ }^{30}$ Sobre la inteligibilidad de deberes no asociados a derecho subjetivo alguno y viceversa, Камм (2002), pp. 486-513. 
es instrumental a un fin colectivo ${ }^{31}$. Al trasladar el injusto desde la esfera de la acción a sus efectos, determinar si discriminamos depende no solo de cómo nos comportamos frente a otro ceteris paribus, sino, más bien, de las consecuencias mediatas de nuestro actuar.

Una forma distinta de ver la relación entre lo individual y colectivo de la discriminación es entender que su encuentro se produce no en la aplicación de los deberes de evitarla, sino en su instauración. Para calificar si un comportamiento en específico constituye discriminación no es necesario mirar los impactos que haya tenido. Sin embargo, en la definición de qué tipos de comportamientos debiesen ser cubiertos por las reglas antidiscriminación las consideraciones a desventajas colectivas son insoslayables ${ }^{32}$.

John Gardner propuso una forma interesante de distinguir los deberes propios de la discriminación para mostrar que es un injusto que no puede definirse sin atender a las razones por las que tratamos de manera distinta a ciertas personas ${ }^{33}$. El deber de no matar, por ejemplo, siempre está constituido por una misma circunstancia (poner fin a la vida de una persona). Las razones por las que alguien mata pueden importar en derecho para justificar al infractor, pero no configuran el contenido central del deber. No discriminar, en cambio, es un deber que resulta ininteligible sin referencia a las razones que están detrás de su infracción: estas son las que configuran la ofensa misma. Negar el acceso a un grupo de lectura a alguien porque "elevará mucho la discusión literaria debido a que es muy culto e inteligente" no lo hace víctima de discriminación -con independencia de que se trate de una determinación injusta y el interesado sienta frustración-; la misma negativa a una candidata por ser mujer, sí lo es. Y es discriminación aun cuando quien implemente la diferencia no tenga la intención de discriminar o, incluso, tenga otras razones que parezcan muy legítimas para hacerlo (como el club privado que al negar acceso a la mujer por razones raciales solo buscaba resguardar la economía de su negocio).

¿Y cómo identificamos las razones que determinan que un acto sea discriminatorio? Nos parece que estas razones no pueden descubrirse mediante un método analítico puro, sino que dependen de nuestras ac-

${ }^{31}$ Esta idea parece ser cercana a la visión social de los derechos que considera que los derechos subjetivos no pueden ser ejercidos en contra de su "misión social". Véase, JosseRAND (1939), p. 10 ("nos droits ne peuvent se réaliser à l'encontre et au mépris de leur misión sociale").

${ }^{32}$ Se ha argumentado que la legislación antidiscriminación (inclusive las reglas de discriminación directa) es un proyecto que persigue fines redistributivos por medios deontológicos que se centran en la responsabilidad de los agentes, sus faltas e intenciones. En este sentido, Somek (2011), p. 93.

${ }^{33}$ Gardner (2018), p. 6. 
ciones colectivas como sociedad ${ }^{34}$. La discriminación no es la misma en Chile que en otros lugares.

Pasados casi treinta años desde el fin de la dictadura, el PNUD dio cuenta que los avances institucionales, económicos y sociales que posicionaban a Chile como el país con mejor índice de desarrollo humano de la región, se opacaban por un problema de desigualdad ${ }^{35}$. En parte, esto se mostraba en el trato diferenciado que afectaba a ciertos grupos de personas. Uno de los propósitos del informe fue identificar "¿quién sufre malos tratos y quién los perpetra? ¿̇en qué contextos son más frecuentes y por qué razones ocurren?". Estas preguntas formuladas por el PNUD son fundamentales, porque muestran que para saber si discriminamos es necesaria una mirada colectiva que muestre quiénes sufren malos tratos y por qué los sufren.

Algunos podrán discrepar de este punto; bastaría con definir en abstracto qué propiedades de las personas no pueden emplearse como una razón para deliberar, en la medida que expresan menosprecio. Podríamos, incluso, con cierta facilidad, consensuar estas propiedades (solo los discriminadores dudarían de incluir identidad racial, por ejemplo). Pero ¿cómo anticiparse a estas diferencias sin una historia que nos haga consciente de ellas? ${ }^{36}$. Son las prácticas de una comunidad las que determinan que cierto

${ }^{34}$ Por eso es que muchas de las reglas de derecho internacional de los derechos humanos que han servido de base para prohibir la discriminación han recurrido a ciertas "categorías protegidas" o "categorías sospechosas", que a lo largo de la historia han estado vinculadas a un trato discriminatorio; véanse: art. 2 de la Declaración Universal de Derechos Humanos; arts. 2 y 26 del Pacto Internacional de Derechos Civiles y Políticos; art. 2 de la Convención de los Derechos del Niño; art. II de la Declaración Americana de los Derechos y Deberes del Hombre y arts. 1 y 24 de la Convención Americana sobre Derechos Humanos. Por eso también es que la jurisprudencia internacional en materia de derechos humanos ha desarrollado estándares especiales de justificación y carga de la prueba en los casos en que una de estas categorías especiales está involucrada; en el caso de la Corte Interamericana de Derechos humanos véanse los casos A. y niñas con Chile (2012), N. y otros con República Dominicana (2015), G. y otros (Radio Caracas Televisión) con Venezuela (2015), G. y otros con Ecuador (2015); en el caso del Tribunal Europeo de Derechos Humanos véanse los casos A., C. y B. con Reino Unido (1985); I. con Austria (1989); Chipre con Turquía (2001) y N. y otros con Bulgaria (2005). Sobre la relevancia de estas categorías en el desarrollo del derecho internacional de los derechos humanos en materia de discriminación véanse Corte Interamericana De Derechos Humanos (2019), pp. 26-30 y 39 y ss.; Comisión Inter-Americana de Derechos Humanos (2019), pp. 56-65 y 77 y ss.

${ }^{35}$ PNUD (2017).

${ }^{36}$ Los genetistas contemporáneos en general concuerdan en que las clasificaciones raciales carecen de base científica. Véase Tishroff \& KidD (2004), p. 21. Este punto parece dar razón a las tradiciones intelectuales críticas que han trazado la genealogía de las diferencias raciales, argumentando que se trata de diferencias socialmente construidas. Véase McWhorter (2004), pp. 38-59. Una interesante confirmación de esta idea puede 
tipo de interacciones tengan un sentido discriminatorio ${ }^{37}$. Poco plausible sería acusar que el reconocimiento de tierras indígenas es una medida de discriminación del Estado chileno (sin perjuicio de otros defectos o virtudes que pueda tener esa política). Por el contrario, la segregación racial en Estados Unidos ${ }^{38}$, la aplicación de estatutos jurídicos distintos a los colonos israelíes y a los palestinos de la Palestina ocupada ${ }^{39}$, o la reserva de zonas blancas durante el apartheid sudafricano, sin duda, las calificamos como discriminatorias ${ }^{40}$.

En la dirección opuesta, la política antidiscriminación es la base sobre la que puede determinarse en qué consisten los deberes antidiscriminación y quiénes pueden infringirlos. Inscribir estos deberes en una política pública no significa que su aplicación en cada caso particular también sea dependiente de esta política. Para explicarlo podemos recurrir a la diferencia que John Rawls formuló entre justificar una regla y justificar una acción particular que cabe dentro de esta regla ${ }^{41}$. Tomemos las mismas preguntas que plantea este autor para explicar la diferencia, pero adaptándolas al caso del sauna expuesto en la primera sección. Una pregunta sería, "¿por qué la Corte de Apelaciones de Santiago aplicó una sanción al club?" La respuesta sería: "Porque discriminó a una mujer coreana". Otra pregunta es: “¿Por qué la ley prevé sanciones para quienes discriminan?”. Las respuestas podrían ser: "Para proteger a las personas de distinciones arbitrarias", pero también podría ser: "Para que las personas no se comporten de un modo que aumente las diferencias entre los distintos grupos de nuestra sociedad".

encontrarse en la aparición, cada vez más fuerte, de una conciencia racial de la "raza blanca" en Estados Unidos los últimos años. Sobre esto último, véase el reciente reportaje editorial publicado en The Economist (2021).

${ }^{37}$ Esta forma de identificar la discriminación es lo que explica por qué la declaración del voto de mayoría del Tribunal Constitucional que iguala la imposibilidad de contraer matrimonio por personas del mismo sexo en Chile con la imposibilidad de matrimonios polígamos, entre niños, “arreglados” por los padres o contraídos masivamente no solo es desafortunada, sino en extremo impertinente. Véase V. con Servicio de Registro Civil e Identificación (2020), sentencia recaída en el requerimiento de inaplicabilidad respecto del inciso final del art. 12 de la Ley n. 20830 y de la frase "siempre que se trate de la unión entre un hombre y una mujer" contenida en el inciso primero del art. 80 de la Ley n. ${ }^{\circ} 19947$.

${ }^{38}$ Un reporte de distintas medidas de discriminación en Estados Unidos durante el siglo XIX y la primera mitad del xx, en McWilliams (1945).

${ }^{39}$ Un detalle de las diferentes estructuras y medidas de discriminación de Israel contra los palestinos, que permiten calificar a ese Estado como un régimen de apartheid en Human Rights Watch (2021) y B’TSELem (2021).

${ }^{40}$ Comité Especial de Naciones Unidas sobre las Políticas de Apartheid del Gobierno de la República de SudÁfrica (1964).

${ }^{41}$ RAWLS (1955). 
Nuestro punto es que en el caso de la discriminación esta segunda respuesta es ineludible. Aunque en cada instancia solo nos importe la lesión individual al discriminado, la práctica de instaurar una legislación antidiscriminación sí necesita atender, no solo a lo que hace una persona en particular, sino a lo que ocurre en un contexto social más amplio. Para detectar si al discriminado le estoy generando un daño discriminatorio, necesito saber qué tipo de diferencias son inaceptables. Sin atender a las "propiedades que marcan la diferencia en distintos tipos de interacciones sociales" ${ }^{42}$, no podemos detectar la discriminación (sin perjuicio de que una vez detectada, la aplicación de las reglas solo dependa de la posición individual del afectado y no de las metas colectivas que pueda tener la política anti-discriminación). Esta forma de construir los deberes de no discriminar -que hacen impermisibles ciertas razones en determinados contextos con independencia de los prejuicios e intenciones de quien discrimina- permite que, pese a que la aplicación de las reglas antidiscriminación solo enfrente actos individuales, sea también una forma de romper el círculo de la discriminación ${ }^{43}$.

Detectar dónde está lo colectivo e individual de la discriminación es clave para entender cómo estos compromisos pueden insertarse en las relaciones jurídicas entre partes privadas a las que la ley confiere autonomía. Por cierto, esta no fue una preocupación recogida en las codificaciones 230 civiles. Todo lo contrario, en el caso del Código Civil chileno, varias normas que directamente discriminaban y aún hay disposiciones que dan cuenta de ominosos sesgos de género ${ }^{44}$. Los compromisos antidiscriminación hacen exigible una reforma a esas disposiciones. Pero más allá de modificaciones legislativas puntuales, creemos que esta forma de entender la concurrencia de consideraciones colectivas e individuales en las reglas que combaten la discriminación puede ayudar, en gran medida, a construir de manera más general cuál es la relación entre los deberes que surgen de ellas y el derecho privado.

\section{TENSIONES ENTRE DERECHO PRIVADO Y DISCRIMINACIÓN}

Para analizar la relación entre deberes de no discriminación y derecho privado, una idea básica que podemos tomar como punto de partida es que, entre las reglas centrales del derecho privado, están aquellas que confieren competencia a las personas para determinar y conducir libremente sus

\footnotetext{
${ }^{42}$ Véase Hellman (2008), pp. 25-26; Lippert-Rasmussen (2013), p. 32.

${ }^{43}$ GARDNer (2018), p. 31 (sosteniendo que la política antidiscriminación es verdaderamente "política").

${ }^{44}$ Sobre reformas al Código Civilen razón de consideraciones constitucionales de igualdad, véase TAPIA (2007), pp. 155-199.
} 
preferencias y opciones en la vida. Este orden facilita -o, con mayor vigor, constituye- relaciones que tienen como premisa la autodeterminación ${ }^{45}$.

La existencia de estos espacios de autodeterminación, tan centrales para el derecho privado, plantea la pregunta por la forma de delimitar la libertad de los individuos con la persecución de objetivos colectivos. Pareciera ineludible que la competencia privada concedida de acuerdo con los ideales de una sociedad liberal permita mantener o llegar a situaciones de radical desigualdad en calidad de vida y en oportunidades ${ }^{46}$.

Por eso, desde muy antiguo, los ámbitos en que los privados gozan de libertad para autodeterminar sus relaciones han convivido con medidas que, desde el poder público, buscan fortalecer o alcanzar algunos objetivos colectivos ${ }^{47}$. De hecho, quizá con la excepción de algunos defensores

${ }^{45}$ Una interesante reflexión sobre el valor del derecho privado a partir de su relación con las relaciones que típicamente regula en GARDNER (2017). El rasgo constitutivo del derecho privado en las relaciones entre particulares hace que ocupe un lugar importante en la tradición política liberal. HAYEK (2006) es el que este punto de la manera más enfática; Pashukanis (1976) acusa un dominio histórico de las categorías y formas del derecho privado. Aunque la existencia de un espacio de autodeterminación con estas características no debe llevarnos a identificar al derecho privado como el derecho del ámbito personal o privado, sí podemos reconocer que este ámbito ocupa un lugar central en las pretensiones y expectativas normativas que surgen de una interacción social de este tipo. Sobre la relación entre el ámbito privado y la distinción entre derecho público y derecho privado, véase el trabajo de AzAr (2021), passim.

${ }^{46}$ Este punto, que parece casi un corolario de la libertad de las personas para participar en las relaciones de intercambio que estimen convenientes, no se plantea necesariamente en contra del liberalismo político. Por el contrario, la posibilidad de que los intercambios libres se produzcan de manera tal que, aun partiendo desde una repartición igualitaria de los recursos, se llegue a una situación de extrema desigualdad es asumida por autores liberales que sostienen tesis muy distintas entre sí. Una buena muestra de esto es el famoso ejemplo de Wilt Chamberlain, propuesto por Nozick (1974), pp. 160-164 y discutido, sin refutar la premisa, por DwORKIN (2000), p. 111 y ss. De acuerdo con este ejemplo, si la gente puede libremente transferir su propiedad a otros de acuerdo con su voluntad, es inevitable que en una sociedad, que, por ejemplo, tenga suficientes fanáticos del basquetbol, los jugadores famosos como Wilt Chamberlain -a la época, célebre jugador de los Los Angeles Lakersterminasen acumulando bienes en cantidad mucho mayor a la del resto. La única manera de evitarlo es el uso de la regulación estatal, de ahí que la diferencia entre los distintos autores esté en las medidas que resultan admisibles para corregir el resultado, y no en el resultado mismo. Un comentario al ejemplo desde una defensa del socialismo en CoHEN (1977).

${ }^{47}$ Un ejemplo en relación con los antecedentes clásicos de la idea de Estado social y su relación con la iniciativa privada puede verse en los complejos sistemas de crédito estatal con intereses para el uso de la tierra que, desde la época del emperador Nerva, los romanos usaron para financiar la manutención de los niños desamparados en los municipios del Imperio, de las que da cuenta BARROw (1950), p. 107 y ss. Incluso, desde quienes plantean la total indiferencia del derecho privado con los fines distributivos, esto se construye asumiendo la existencia de otros ámbitos en que la distribución sí es asumida como una tarea posible, si es que no necesaria. Así, por ejemplo, Ripstein (2000), p. 766. 
extremos del libertarismo, la convivencia de la libertad privada con la regulación del poder público es un aspecto que siempre ha estado presente en los fundamentos teóricos del liberalismo ${ }^{48}$.

La interacción entre interés público y autonomía privada se ha hecho marcadamente presente en la teoría del derecho privado ${ }^{49}$. De un tiempo a esta parte, las discusiones las han protagonizado posturas que ven en él un valor no instrumental y posturas funcionalistas, por lo general asociadas al análisis económico del derecho, que ven al derecho privado como un mecanismo más en la consecución de objetivos de política pública.

El debate sigue abierto, pero incluso entre quienes ven al derecho privado como un elemento más de política social, existe consenso en que se trata de una herramienta que depende de la autonomía de las personas para ser ellas mismas protagonistas y fiscalizadoras del sistema de derechos que articula y protege sus espacios de libertad ${ }^{50}$.

Eso nos deja en la siguiente situación: desde donde lo miremos, el derecho privado aparece ligado a un espacio de autonomía personal en que el protagonista de la toma de decisiones es el individuo. Sin embargo, en una sociedad con amplios espacios de relevancia en manos de privados, la consecución de cualesquiera objetivos políticos depende, críticamente, de la colaboración y participación de estos agentes. Compromisos sociales 232 que van desde la provisión de salud pública o educación hasta la preservación de la competencia en los mercados, pasando por la protección del consumo y la lucha por la conservación de la naturaleza, en mayor o menor grado, revitalizan la pregunta por la forma en que las relaciones de derecho privado pueden frenar o canalizar la obtención de cualesquiera sean los objetivos de la comunidad política.

Por las razones que vimos en la sección anterior, la implementación de un compromiso político contrario a la discriminación participa de esta tensión con especial intensidad. La construcción de deberes de no discri-

${ }^{48}$ Por todos, véanse las ideas de John Stuart Mill sobre los límites de la actividad estatal en Alexander (1999), p. 122 y ss., un intento de actualizar esas ideas en Feinberg (1987). La más conocida versión extrema de la incompatibilidad entre la libertad y la regulación estatal es la de Nozick (1974), que reduce el campo de actuación del Estado a la provisión de las condiciones mínimas de seguridad para asegurar las reglas de la propiedad privada en la forma de un nightwatch State (especialmente en p. 88).

${ }^{49}$ Sobre la incorporación de intereses públicos y colectivos en el derecho privado, véase Collins (2007), pp. 1-21.

${ }^{50}$ Véanse, desde una defensa fuerte del análisis instrumental del derecho privado, LANDES \& Posner (1987), passim. Un análisis que contrapone las perspectivas instrumentales y lo que podrían llamarse teorías del valor intrínseco del derecho privado en GaRDNER (2017). En Chile, sobre la concurrencia de aspectos públicos y privados en el derecho privado véase BARRos (2001) y, con una perspectiva crítica de la forma tradicional de enfrentar la distinción entre derecho público y derecho privado, AzAR (2021). 
minación directa requiere, para ser efectiva, la identificación de ciertas categorías de distinción entre personas que en la historia han sido marginadas en razón de ciertas propiedades. Y el problema es que la identificación de estas categorías es en especial sensible a elementos sociales y políticos que, por lo general, exceden el ámbito del derecho privado ${ }^{51}$.

En el caso de las formas indirectas de discriminación, hemos visto que trasladar el injusto desde la esfera de la acción a sus efectos supone, en forma mucho más clara, evaluar las consecuencias mediatas de nuestro comportamiento a la luz de compromisos públicos. Tradicionalmente esto puede no ser un problema. Ya vimos que la autonomía de los agentes privados ha estado acompañada desde antiguo por un espacio en que resulta legítimo que la comunidad persiga fines redistributivos que resultan esenciales. Sin embargo, la consideración de los elementos colectivos de la discriminación supone una tensión adicional a las formas tradicionales que hemos usado para conseguir esos objetivos redistributivos.

La contraposición con el caso de los impuestos permite verlo con claridad. Mientras el sistema de impuestos permite redirigir, a través de la acción del Estado, los recursos desde quienes tienen más a quienes tienen menos, en una forma relativamente coherente, lo mismo no ocurre con las medidas que suelen emplearse para enfrentar los casos de discriminación indirecta y las desventajas cuya corrección requiere de acciones afirmativas. En la mayoría de los países, la medida en que cada quien contribuye a financiar las prestaciones del Estado depende directamente de la forma en que los recursos están repartidos. Quien tiene más recursos contribuye en mayor medida que quien tiene menos, porque está en una mejor posición para hacerlo. Por el contrario, la imposición de un deber de no cometer discriminaciones indirectas depende, en primer lugar, de la circunstancia de interactuar con personas que pertenecen a alguno de los grupos sobre los que podría caer la protección de estos deberes. Volvamos al ejemplo de la academia. Al menos en un nivel básico, la pregunta por la medida en que fue posible exigir a la academia un compromiso con la inclusión de discapacitados no se planteó porque la academia estuviese en una especial posición de ventaja para producir esta inclusión, sino simplemente porque una persona afectada por una discapacidad motora se interesó en la academia y quiso ser incluida en ella.

${ }^{51}$ Véase Gardner (2018) y, con un enfoque en la forma en que los deberes de no discriminar tensionan los mecanismos tradicionales de legitimación de la intervención o regulación del poder público, GARDNER (1989), p. 2 y ss. El punto puede verse, con carácter muy general, en el contexto de la relevancia que tienen las reglas constitucionales y su interpretación jurisdiccional en la actualización de compromisos políticos en materia de principio, véase DwORKIN (1986), p. 381 y ss. 
De esta manera, uno y otro tipo de medidas para enfrentar la discriminación trae consigo la imposición de deberes que tensionan no solo con la autonomía de los privados, sino, también, las formas tradicionales con las que hemos justificado la regulación sobre esta autonomía.

La pregunta que se plantea es, entonces, de qué forma puede resolverse esta tensión. Aunque la interrogante está abierta, hay un punto de partida que resulta conocido para enmarcar esta cuestión: las distintas perspectivas sobre la constitucionalización del derecho privado. En la mayoría de los países que cuentan con estatutos destinados a prohibir ciertas formas de discriminación, incluyendo a Chile, el fundamento de la proscripción está, en mayor o menor medida, en algunos de los derechos fundamentales reconocidos en la Constitución ${ }^{52}$.

El efecto de la Constitución y su influencia en las relaciones de derecho privado ha sido estudiado desde diferentes perspectivas ${ }^{53}$. Sin embargo, de entre todas estas alternativas, hay una que resulta en especial pertinente para el análisis de la cuestión que nos detiene. Se trata de la distinción entre dos soluciones posibles al conflicto entre las reglas y principios constitucionales y las reglas y principios del derecho privado: la vía de complementariedad y la vía de subordinación.

En líneas muy gruesas, una solución de complementariedad existe 234 cuando los derechos constitucionales afectan al derecho privado no sustituyéndolo, sino informando la manera en que operan sus mecanismos típicos de solución de conflictos, que seguirán siendo los únicos llamados a resolver las disputas entre particulares que típicamente lo integran. De esta manera, los dispositivos que implementan las reglas y principios constitucionales en el ámbito regulado por el derecho privado no son los de la Constitución, sino los del propio derecho privado.

Por el contrario, la tensión entre derecho privado y derechos constitucionales se resuelve en la subordinación cuando estos últimos no solo están llamados a influir en el derecho privado, sino que lo gobiernan en forma directa. Es decir, aunque cada relación entre particulares esté regida por las instituciones de derecho privado, estas son entendidas como meras herramientas para canalizar la Constitución hasta estas relaciones. Por eso, en caso de conflicto entre las reglas de uno u otro tipo, debe primar el test de proporcionalidad propio del derecho constitucional ${ }^{54}$.

${ }^{52}$ Young (2011), pp. 16-47; Cherednichenko (2007), pp. 1-25; en particular sobre la relación comúnmente reconocida entre la no discriminación y la igualdad, véase HELLMAN \& Moreau (2014) y los casos A. con Chile (2012); N. y otros (Dirigentes, miembros y activista del Pueblo Indígena Mapuche) con Chile (2014) y E. con Perú (2014), citados más atrás.

${ }^{53}$ Un exhaustivo análisis de las diferentes perspectivas posibles para estudiar este fenómeno en el derecho europeo en Young (2011).

${ }^{54}$ Una postura favorable a esta solución en el trabajo de KumM (2006), passim. 
La existencia de una u otra solución tiene importantes consecuencias institucionales. Elegir la vía de la subordinación, en los hechos, implica entender que los jueces están autorizados, en cada caso que se les presente, a resolver el conflicto intersubjetivo aplicando de manera directa los bienes constitucionales que se encuentren en juego. Por el contrario, si se elige la vía de la complementariedad, la existencia de derechos constitucionales implicados en cada caso de discriminación no es suficiente para que el problema pueda entenderse resuelto y, en cambio, se hace necesaria la intervención legislativa o regulatoria de los organismos públicos (por lo general, aquellos que cuentan con legitimidad democrática $)^{55}$.

$\mathrm{Si}$ en el proceso constituyente chileno se decide incorporar un compromiso constitucional contrario a la discriminación, se deberá escoger, al menos como punto de partida, entre una de estas dos alternativas. Por eso, es relevante preguntarse si en nuestra práctica constitucional actual se ha tomado opción por una u otra.

En principio, en Chile existen elementos que llevan a pensar que se ha decidido por la vía de la complementariedad. En sede laboral y de consumo se han adoptado compromisos de inclusión que han asumido la forma de una ley ${ }^{56}$. Es decir, se ha entendido que, a pesar de las garantías constitucionales vigentes, es necesaria la intervención del legislador para regular la forma y los casos en que estos compromisos deben implementarse. Y esa forma legislativa ha pasado a insertarse en el conjunto de reglas y principios propios del ámbito intervenido.

Sin embargo, esta es una respuesta solo parcial. Existen otros elementos que llevan a concluir que, en verdad, en Chile está abierta la vía de la subordinación. El principal de ellos es la acción constitucional de protección.

Desde su creación en 1976, la acción de protección es la principal vía para obtener amparo jurisdiccional de los derechos constitucionales. $\mathrm{Y}$ se trata de una puerta extraordinariamente amplia a la jurisdicción

${ }^{55}$ La forma en que las sociedades resuelven cuándo es necesaria la intervención legislativa y cuándo, en cambio, los problemas pueden resolverse a través de las decisiones de los jueces, constituye uno de los más interesantes y debatidos puntos de la teoría del derecho. Para efectos de este trabajo, nos interesa destacar que, en buena medida, el debate por el efecto de las reglas constitucionales sobre los ámbitos legislativos específicos que existen debajo de ellas es absolutamente reconducible a este problema: allí donde los vacíos o conflictos de la legislación se pueden resolver en forma directa con principios constitucionales, la nueva intervención legislativa aparece innecesaria. En cambio, donde esto no es posible, la intervención del juez aparece como una intromisión, con frecuencia catalogada de ilegítima, en los espacios que corresponden a las autoridades democráticas. Sobre este punto véanse DwORKIn (1986), pp. 357-379 y ATria (2016), pp. 128-131. Un análisis de los ciclos de cambio doctrinario, jurisprudencial y legislativo en el contexto del derecho privado en BARRos (2018), passim.

${ }^{56}$ Arts. 2, 485, 489 y 489 bis del Código del Trabajo; art. 3 letra c) de la Ley n. ${ }^{o} 19496$. 
constitucional. No tiene limitaciones de sujeto activo ni pasivo, ni tiene como condición agotar el resto de las vías jurisdiccionales alternativas para resolver el conflicto. Así, esta acción permite que cualquier persona cuestione, sin distinción, actos de autoridad y de particulares ${ }^{57}$.

Llevando el punto al derecho privado y su relación con la Constitución, aunque a veces los tribunales superiores encargados con el conocimiento de esta acción se han mostrado deferentes con las reglas y principios del derecho civil, en muchos otros casos esta acción ha llevado a reemplazar el equilibrio de intereses propio de la adjudicación civil por el examen de proporcionalidad del derecho constitucional ${ }^{58}$.

En lo que importa, esto equivale a una solución de subordinación cada vez que, en el contexto de una acción de protección, un conflicto entre privados que podría ser resuelto con las reglas, principios y formas de adjudicación del derecho privado, es, en definitiva, resuelto únicamente a la luz de los derechos constitucionales implicados. Cuando esto ocurre, la relación interpersonal que subyace al conflicto jurídico de las partes deja de ser racionalizada con las formas del derecho privado y, en cambio, pasa a ser resuelta con la forma propia de la adjudicación constitucional de protección.

Nuestra historia jurisprudencial muestra que esto efectivamente ha 236 ocurrido. El punto es difícil de trazar, porque tras la expansión de la acción de protección pueden encontrarse causas distintas, que van desde graves lesiones a derechos que requieren rápida cautela, a situaciones en que el conflicto se explica por un déficit legislativo ${ }^{59}$. Con todo, incluso en el contexto de relaciones que se encuentran plenamente cubiertas por el derecho privado, el recurso de protección ha reemplazado el análisis civil por la ponderación de derechos constitucionales vía test de proporcionalidad ${ }^{60}$.

El segundo elemento que muestra, en los hechos, la opción de nuestro ordenamiento por subordinar el derecho privado a la Constitución es el compromiso legislativo explícito que en Chile se asumió a través de la Ley n. ${ }^{\circ} 20609$, que establece medidas contra la discriminación. Podría pensarse que, dado que lo que consideramos discriminatorio depende en

${ }^{57}$ Jana (2021), pp. 96-97.

${ }^{58}$ Sobre este fenómeno, con abundantes citas de jurisprudencia, véanse ATRIA (1997), pp. 89-90 y JANA y MARÍN (1996); una revisión reciente del efecto de la acción de protección en el ámbito civil, con enfoque crítico de sus efectos, en Jana (2021), pp. 96-103.

${ }^{59}$ Un buen ejemplo de lo anterior es la evolución de la jurisprudencia en relación con la procedencia de la acción constitucional en el ámbito de la conservación del ambiente; un análisis jurisprudencial del punto en URRUTIA (2004), p. 271 y, con énfasis en el efecto que tiene la dictación de leyes especiales en la procedencia de la acción en razón de su naturaleza cautelar, Fermandois y Chubretovic (2016).

${ }^{60}$ JaNA y MARÍN (1996); un análisis reciente en JanA (2021), pp. 98-101. 
buena medida de concepciones y datos sociales abiertos, el sentido de esta ley fue situar el problema desde estas concepciones sociales para insertarlo en forma diferenciada al contexto particular de la relación en que la discriminación pudiese producirse. Algo similar, pero con mayor alcance, a lo que se buscó con la formulación de reglas en sede laboral y de consumo.

Sin embargo, esto no se logró. La ley creó una acción especial que tiene el sentido preciso de permitir a cualquier persona reclamar de un acto discriminatorio ante el juez civil para obtener la remoción del acto y una multa. Hasta ahí, no hay nada que muestre en la ley una opción por la subordinación de la relación de que se trate a los principios y derechos constitucionales. No obstante, la ley también define qué es lo que cuenta como acto de discriminación a efectos de intentar la acción creada:

"Para los efectos de esta ley, se entiende por discriminación arbitraria toda distinción, exclusión o restricción que carezca de justificación razonable, efectuada por agentes del Estado o particulares, y que cause privación, perturbación o amenaza en el ejercicio legítimo de los derechos fundamentales establecidos en la Constitución Política de la República o en los tratados internacionales sobre derechos humanos ratificados por Chile y que se encuentren vigentes" ${ }^{\prime \prime}$.

De este modo, la ley no determina de manera diferenciada lo que es discriminatorio en distintos contextos, sino que se acude a la misma fórmula de la acción de protección constitucional. En uno y otro caso lo relevante es la privación, perturbación o amenaza de un derecho fundamental por un acto que, a su vez, no pueda justificarse en el ejercicio de otro derecho ${ }^{62}$.

Así, aunque existió una iniciativa específica destinada a concretar la agenda contra la discriminación desde el plano constitucional, ello no afectó en lo más mínimo la forma en que el juez, ahora civil, deberá resolver el problema con el que es enfrentado ${ }^{63}$.

Más atrás indicamos que lo verdaderamente característico de una solución que opta por la subordinación del derecho privado a la Constitución para resolver un conflicto intersubjetivo de derechos fundamentales no

${ }^{61}$ Art. 2 de la Ley n. ${ }^{\circ} 20609$.

${ }^{62}$ Una crítica a esta forma de resolver el conflicto, sobre la base que implica una jerarquización inconstitucional del resto de los derechos por sobre la no discriminación, en DíAz DE VALDÉs (2013), p. 280 y ss. y (2014), pp. 167 y 175; en un sentido similar, DíAZ (2013), pp. 652-658.

${ }^{63}$ Esta similitud en la forma de resolver los conflictos ha dado origen a una jurisprudencia que se ha visto enfrentada a la necesidad de subsanar los vacíos e indeterminaciones dejados por el texto legal; en este sentido, el trabajo de DíAz DE VALDÉs (2017). 
es la jerarquía de la regla que resuelve el conflicto. Lo verdaderamente definitorio de esta vía es la forma en que se mandata y faculta al juez a considerar estos derechos en la solución del caso. Una opción es hacerlo a partir de las reglas destinadas a canalizar esos derechos en el contexto específico de las relaciones que el derecho privado facilita o constituye. La otra, es a través de un examen de proporcionalidad abstracto que, en caso de conflicto con estas formas, debe reemplazarlas ${ }^{64}$. Ambas vías responden a la importante pregunta institucional relativa a qué órgano y de qué forma se debe determinar lo que exige la protección de derechos constitucionales, y en particular, el compromiso antidiscriminación ${ }^{65}$.

Puede que una primera lectura de la ley no sea explícita en relación con la elección de la segunda vía. Pero la implementación de una vía de complementariedad hubiese exigido que, en la forma en que se ha hecho en el derecho comparado, la ley diese lugar a la consideración y diferenciación de distintos tipos de relación en que la discriminación arbitraria puede producirse. A falta de esta diferenciación, la única herramienta del juez será traer el derecho constitucional a la primera línea y decidir si un derecho fundamental fue arbitrariamente privado, perturbado o amenazado o si, en cambio, fue solo limitado por el ejercicio de otro derecho. Es decir, solo puede resolver con el derecho constitucional.

\section{Deberes DE NO DISCRIMINAR EN EL DERECHO PRIVADO}

Identificar qué diferencias constituyen malos tratos, quién los perpetra y los sufre, y en qué interacciones resultan inaceptables es una tarea ineludible para construir deberes antidiscriminación. No solo porque así podemos encontrar dónde está el problema y cómo combatirlo; también porque nos permite detectar qué es la discriminación en una sociedad determinada. Esta es la única manera de definir el contenido de los deberes para enfrentarla.

${ }^{64}$ Una de las principales objeciones al test de proporcionalidad es que supone la ponderación de derechos o valores inconmensurables y, de ese modo, se oculta la complejidad de los problemas morales de fondo que implican los casos, véase TsaKIRAKYs (2009), pp. 468-493. Aunque se ha argumentado en forma convincente que la inconmensurabilidad no es un problema exclusivo ni insuperable de la ponderación, de todos modos se han detectado otras patologías que deben considerarse al momento de optar por esta vía de racionalidad, véase ENDiCOTT (2013), pp. 1-34. Para una defensa del test de proporcionalidad, Alexy (2010), pp. 21-32.

${ }^{65}$ Esta pregunta institucional es planteada de manera clara en EndicotT (2013), p. 34 y, con una perspectiva muy favorable a la aplicación de los principios y formas de adjudicación del derecho constitucional, en Kumm (2006), p. 346 y ss. 
Eso hacen las leyes cuando prohíben a determinados agentes (proveedores, empleadores, órganos del Estado, por ejemplo) hacer diferencias en razón de ciertas categorías (ya sea orientación sexual, género, origen, clase social, religión). Eso también hacen los distintos tratados y decisiones internacionales que han identificado esas mismas categorías como las más frecuentemente vinculadas a tratos discriminatorios ${ }^{66}$. La legislación chilena, sin embargo, lo hace a medias. Como señalamos, nuestra ley todo lo deja abierto a la ponderación del caso a caso, subordinando la decisión al balance directo de los distintos derechos constitucionales implicados. Por eso, nos parece que, al fin y al cabo, no da ningún criterio para determinar qué es la discriminación y qué deberes son necesarios para enfrentarla. Resulta difícil construir una política antidiscriminación sólida si la dejamos entregada a la sumatoria de decisiones judiciales. Creemos necesario configurar deberes que sean claros, ya sea en el ámbito legislativo o, al menos, doctrinario.

Nuestra intención es contribuir a esta labor desde el derecho privado. No buscamos identificar qué deberes antidiscriminación son oportunos. Solo detectamos algunos deberes, ya vigentes o que podrían surgir a propósito de las discusiones constitucionales, que conflictúan con reglas de autonomía paradigmáticas del derecho privado. ¿Supone este tipo de deberes la derogación de estas reglas?

\section{Deber de no discriminar a quien tenemos en frente}

La relación entre derecho privado y antidiscriminación es compleja. Al menos en un sentido convergen: el reconocimiento de un estatus moral igualitario. El principio de igualdad ante la ley formulado por el liberalismo clásico es el punto de partida del sistema de derecho privado ${ }^{67}$. Esto es lo que expone el art. 55 del Código Civil que considera que "son personas todos los individuos de la especie humana, cualquiera que sea su edad, sexo, estirpe o condición". La regla general de capacidad del art. 1446, del mismo modo, en principio reconoce capacidad a todas las personas, limitándose las incapacidades a casos especiales y solo con fines de protección (art. 1447). Ambos tipos de capacidad, de goce y ejercicio,

${ }^{66}$ Véanse, por ejemplo: arts. 2 y 26 de la Declaración Universal de Derechos Humanos, art. 2; Pacto Internacional de Derechos Civiles y Políticos; art. 2 de la Convención de los Derechos del Niño; art. II de la Declaración Americana de los Derechos y Deberes del Hombre y arts. 1 y 24 de la Convención Americana sobre Derechos Humanos.

${ }^{67}$ Sobre la vigencia de este principio en el derecho privado, con referencia al ordenamiento español, véase BERCOVITZ (1990), passim. Una discusión sobre la noción de igualdad alojada en las instituciones del derecho privado en Dorfman (2018). Sobre la igualdad como una noción estructural central del derecho privado sucesorio, SALAH (2019), passim. 
son constitutivas de las personas como agentes con la misma autonomía para deliberar sobre sus propias vidas.

Pero, al mismo tiempo, el reconocimiento de este estatus formal igualitario es un fundamento que permite la discriminación: todas y todos tenemos igual autonomía, incluso para discriminar ${ }^{68}$. Así lo confirman las reglas del derecho de contratos y de la propiedad. La libertad contractual comprende la de escoger a la contraparte contractual; la autoridad normativa del propietario le da el poder de excluir. ¿'Pueden estas libertades ser consistentes con un deber de no discriminar? ${ }^{39}$

El deber del club de dar acceso a la mujer coreana a pesar de que ello pudiere molestar a otras socias ${ }^{70}$; la obligación de un hotel de dueños cristianos, que administran su negocio conforme a sus convicciones religiosas, de dar hospedaje a una pareja de dos hombres que solicitaron una habitación ${ }^{71}$; el deber de una pastelería -también de dueños cristianos- de preparar una torta con un mensaje de apoyo al matrimonio entre personas del mismo $\operatorname{sexo}^{72}$; la reforma del testamento de una abuela que no incluyó a su nieto adoptado ${ }^{73}$; la prohibición a los miembros de una comunidad de restringir acceso a espacios comunes a trabajadoras que se

${ }^{68}$ Alain Supiot, en Supiot (2012), p. 45, ha expresado con elegancia las tensiones que atraviesan al principio de igualdad: "En sus formulaciones más modernas y más laicas, el principio de igualdad sigue estando atravesado por esa tensión entre las dos caras de la identidad individual: somos todos semejantes y por ende todos idénticos, y también somos todos diferentes, por ser únicos". Y es precisamente la igual libertad que todas las personas tenemos la que nos permite diferenciarnos del resto: "Dicha singularidad radical del individuo no resulta de factores objetivos que se le impondrían desde el nacimiento, sino que se expresa en el ejercicio de su libertad. Al nacer libre e igual a todos los otros hombres, será en la competencia con todos los demás donde se revelará para sí y para los demás", op. cit., p. 47.

${ }^{69}$ Véase Collins (2013), pp. 71-88 (preguntándose, en particular, si los deberes antidiscriminación suponen cancelar la libertad de elegir a la contraparte contractual). La conclusión de Hugh Collins es que los deberes de no discriminar cambian el foco desde la pregunta por las restricciones de política pública a la ponderación de los derechos constitucionales de las partes involucradas. Contra esa conclusión, nosotros opinamos que los deberes de no discriminar son mejor construidos desde una política pública que se inserta al derecho privado como reglas de orden público, y no desde el test de proporcionalidad.

${ }^{70}$ Servicio Nacional del Consumidor con Centro de Salud y Recreación Gunter Mund y Compañía Limitada (1993).

${ }^{71}$ Véase la decisión de la Corte Suprema de Reino Unido, PB. and HB. v. H. and P. (2013).

${ }^{72}$ Véase la decisión de la Corte Suprema de Estados Unidos, Masterpiece Cakeshop, Ltd. v. Colorado Civil Rights Commission et. al (2018). Compárese esta decisión con la de la Corte Suprema de Reino Unido, en L. v. Ashers Baking Company Ltd. and others (2018).

${ }^{73}$ Véase la decisión del Tribunal Europeo de Derechos Humanos, en AP. and RP. v. Andorra (2006). 
encargan de las necesidades domésticas de los comuneros ${ }^{74}$. Todos estos deberes reducen el espacio de reglas de reconocimiento de potestades paradigmáticas del derecho privado. Es cierto que así también lo hacen varias reglas prohibitivas y las nociones de "orden público" y "buenas costumbres" que se han desarrollado en la tradición del derecho civil. Pero ¿son las consideraciones antidiscriminación impropias en las relaciones de derecho privado? La duda se presenta porque en la configuración de los deberes antidiscriminación hay que mirar más allá de la relación bipolar entre dos partes.

Sin embargo, esa mirada corresponde a quien instaura el deber de no discriminar, y no a quien lo carga. Una vez incorporados dentro del derecho privado, en las relaciones de una persona frente a otra, los deberes de no discriminar pueden plantearse como una delimitación de las esferas de autonomía a partir del mismo principio de igualdad, de modo que se nos esté impedido discriminar a otras y otros. Cuando hacemos una diferencia en razón de ciertas características que en un contexto histórico o social han servido para segregar a algunas personas, degradamos el estatus igualitario que el orden jurídico les reconoce. Alternativamente, esa diferencia de trato puede verse como un daño a la autonomía de la persona discriminada en la medida que hace que sus oportunidades dependan de ciertas características que, conforme a la ley, no debiesen considerarse al deliberar ${ }^{75}$. La discriminación, bajo esta perspectiva, puede internalizarse como un injusto propio del derecho privado. Su fuerza normativa no exige nada más ni nada menos que no discriminar a quien tenemos en frente en una relación bipolar.

Y el derecho privado tiene sus formas para canalizar este deber de no discriminar: deberes de contratar que desplazan en ciertos ámbitos a la libertad contractual, inmisiones autorizadas a la propiedad ajena y, como deber secundario, la indemnización de perjuicios. Otros conceptos indeterminados de la tradición del derecho civil también tienen la ductilidad suficiente para recoger compromisos antidiscriminación. Un acuerdo o una disposición unilateral con contenido discriminatorio puede considerarse que atenta a las buenas costumbres. Un contrato puede ser integrado con obligaciones implícitas de conferir ciertas facilidades a la otra parte desde de la buena fe, como lo hizo la Corte Suprema en el caso de la academia. En esa decisión, las normas antidiscriminación sirvieron para determinar qué obligación era

${ }^{74}$ Una copropietaria acusó de discriminación a la comunidad del edificio del que era parte su departamento al advertir que el reglamento de copropietarios prohibía a las trabajadoras del hogar el uso de la piscina. Véase nota publicada en La Tercera por Soto (2016).

${ }^{75}$ Un planteamiento del injusto de discriminar como una afectación a la autonomía deliberativa de las personas, en Moreau (2010), pp. 143-179. 
razonable integrar al contrato entre la academia demandada y el estudiante demandante, pero no las obligaciones que la academia debía cargar a favor de personas con discapacidad fuera de un contexto contractual.

Una cuestión difícil de definir es si acaso estos deberes deben ser aplicables a todas las personas con independencia del ámbito en que actúen ${ }^{76}$. Por ejemplo, no solo que el proveedor esté impedido de discriminar al consumidor, sino, también, este último al primero (el machista tiene el deber de permanecer en el avión, y no la libertad de abandonarlo, aunque lo pilotee una mujer). Acá no responderemos a esta pregunta ${ }^{77}$. Solo diremos que nos parece que esta respuesta tiene que venir desde fuera (llamemos ese fuera "política antidiscriminación"). Creemos que el derecho privado puede internalizar y hacer propios los deberes antidiscriminación, incluso de modo general para todas las relaciones que regula. De ser así, no es que las libertades paradigmáticas del derecho privado se supriman, solo que quedan incondicionalmente delimitadas. En otras palabras, se conserva la libertad (de contratar, por ejemplo) solo en la medida que no sea discriminatoria (y esa medida no tiene por qué ser poca). Sin embargo, si los deberes son impuestos sin ninguna calificación, a todas las personas y en toda circunstancia (con independencia del papel que representen) , $^{78}$ lo que puede desaparecer -o verse en exceso afectado- no es el derecho

242 privado, sino un ámbito de intimidad que el derecho protege mediante garantías constitucionales distintas de la igualdad y los compromisos antidiscriminación.

\section{Deberes de integrar a quienes han sido marginados}

Un deber de no discriminar a quien tenemos en frente puede ser insuficiente para cubrir los sentidos colectivos de las normas antidiscriminación, sobre todo, si una comunidad política decide adscribir a un fuerte prin-

${ }^{76}$ En Chile, Díaz de VAldés (2018), p. 227, argumenta que la prohibición de hacer diferencias arbitrarias contemplada en el art. 19 n. ${ }^{\circ} 2$ de la Constitución Política de la República no solo es aplicable al Estado, sino, también, a "autoridades privadas", esto es, "personas que, en los hechos, ejercen poder sobre otras, normalmente al interior de cuerpos intermedios"; la misma idea, como justificación normativa a la prohibición de ciertas formas de discriminación entre privados, puede consultarse en DíAZ DE VALDÉs (2014), pp. 155-156. En Khaitan (2015), pp. 196-214, se sostiene que los deberes de no discriminación se justifican en aquellas partes privadas que tienen una "pretensión menor" de libertad negativa y el poder de afectar el acceso a bienes básicos. Véase también Collins (2017), pp. 360-368.

${ }^{77}$ Una argumento moralque en parte justifica y en parte objeta la estructura asimétrica de las legislaciones antidiscriminación (que contemplan deberes de no discriminar aplicables a proveedores, pero no a consumidores) en Dorfman (2020), pp. 175-194.

${ }^{78}$ Pensemos, por ejemplo, en una propietaria que prefiere no arrendar su casa a una persona de determinada etnia a la que asocia hábitos de poca higiene. 
cipio de igualdad. Cuando alguien decide vivir en un barrio en que solo habitan personas blancas y ricas, cuando opta por colegios que educan separadamente a niñas y niños ${ }^{79}$, cuando se inscribe en un club solo de hombres, es probable que no lo haga por una razón discriminatoria contra nadie en particular, pero sin duda recrea las desventajas estructurales y sistemáticas que segregan de esos espacios a ciertas personas ${ }^{80}$.

No es propio de las relaciones jurídicas constituidas por derechos subjetivos, como de forma típica están conformadas las relaciones de derecho privado, atender a los impactos que nuestras acciones producen más allá de la relación bipolar entre dos partes ${ }^{81}$. Es acá donde surge la ineludible pregunta por cómo el derecho privado puede internalizar un deber de interactuar en distintos ámbitos de nuestras vidas con personas diversas, no para evitar un daño a un individuo, sino destinado, principalmente, a reducir las desventajas relativas de todo un grupo de personas. Se trata de un punto en especial sensible porque en las economías de mercado el acceso a fuentes laborales y a distintos bienes y servicios depende, en esencia, de la decisión de partes privadas. Y si valoramos la diversidad y el acceso igualitario a oportunidades, ¿̇por qué no también expandir el círculo de las relaciones de derecho privado, haciéndolo exigible? (por ejemplo, afirmando el deber de la academia de admitir a estudiantes con discapacidad, y no sólo de adaptar su sistema educativo en beneficio de los estudiantes que ya habían sido voluntariamente admitidos). ¿Supondría ello la supresión del derecho privado?

Si cada decisión que tomamos está sujeta a ser revisada según parámetros de inclusión parece desaparecer la estructura del derecho privado que facilita (o constituye) nuestras relaciones interpersonales, reconociendo valor a aquellas formadas por decisiones libres. No porque ello necesariamente quita todo lugar a la autonomía. Las personas comprometidas con el pluralismo se preocupan de optar por modos de vida inclusivos que persiguen reducir la discriminación. La razón es porque si resulta exigible medir los impactos de cada decisión, bajo la eventualidad de que pueda ser revisada según parámetros de discriminación, quien carga con ese deber no puede tener la seguridad de estar cumpliendo con la regla de conducta. Dicho de otro modo, si la discriminación es independiente de las razones que tenga el discriminador, la infracción del deber escapa

\footnotetext{
${ }^{79}$ Véase la decisión de una corte inglesa en el caso HM Chief Inspector v. Interim Executive of Al Hijrah School (2018). Se discutió si acaso constituía discriminación la política de un colegio de proveer educación a niñas y niños, pero por separado.

${ }^{80}$ Se ha reconocido que pueden haber "efectos discriminatorios" sin que exista necesariamente un trato discriminatorio. Véase SEINER (2006), p. 95.

${ }^{81}$ Este punto ha sido hecho en Atria (2004), pp. 24-25, con referencias a Dabin (1955), pp. 121-128.
} 
de su esfera de control, lo que resulta incompatible como regla general en un estado de derecho ${ }^{82}$.

¿No es esta apertura inherente a la misma idea de discriminación indirecta? A fin de cuentas, a esta la define no el criterio de diferencia invocado por quien discrimina, sino la circunstancia de que ese criterio impacta a todo un grupo que comparte una propiedad recogida por la legislación antidiscriminación $^{83}$. ¿Quien toma cualquier decisión tiene la carga de medir de antemano de qué modo su criterio de elección se superpone con otros criterios impermisibles? La manera en que las legislaciones evitan esta carga es reconociendo al agente la posibilidad de justificar su decisión. La delimitación de la discriminación indirecta solo a casos injustificados devuelve el control al agente. Por lo tanto, solo cuando se prefiere una característica que impacta a todo un grupo sin una razón que el derecho define como justificada, un agente incurre en discriminación.

Pero si los deberes de inclusión son delimitados y asignados ex ante en específico a determinados agentes, estos pueden seguir una regla de conducta que, aunque delimite su libertad para decidir, no la vuelve impracticable. Esto es lo que hacen las leyes de paridad en ciertos ámbitos (ya sean aplicables a órganos públicos o a órganos de administración de personas jurídicas de derecho privado). Es una discusión propia de la teoría del derecho 244 privado, definir si se trata de regulaciones redistributivas ajenas a su lógica interna o si insertan en un compromiso pluralista que el derecho privado también debiere compartir ${ }^{84}$. Sin perjuicio de esta discusión, y más allá de las restricciones que significan, las libertades paradigmáticas del derecho privado no se suprimen. La oportunidad de este tipo de deberes, enseguida, es una cuestión política que un regulador diligente y calificado debiese decidir. Cuando se trata de regulaciones claras, las reglas de derecho privado pueden adaptarse y convivir con los compromisos antidiscriminación.

\section{CONCLUSiÓN}

El logro de compromisos políticos contra la discriminación requiere de reglas que impongan, en determinados contextos, deberes de no discriminar que vinculen a las personas en sus relaciones privadas. Sin embargo, la legislación

\footnotetext{
${ }^{82}$ Este problema fue identificado por H. L. A. Hart bajo la etiqueta de "assurance problem", y fue invocado como un argumento para negar una regla general de responsabilidad estricta. Véase HART (1968), pp. 44-47 y GARDNER (2014), pp. 209-2011.

${ }^{83}$ Este punto ha sido hecho por ForAn (2019), pp. 901-929, para argumentar que la discriminación indirecta necesariamente debe construirse como un injusto individual.

${ }^{84}$ Dagan \& Zipursky (2020), p. 16 (argumentando que el derecho privado está comprometido internamente con las reglas de no discriminación).
} 
vigente en Chile no ayuda a determinar qué deberes pueden resultar exigibles a los privados. En cambio, contiene una cláusula general que prohíbe discriminar arbitrariamente, sin delimitar los distintos ámbitos en que se aplican.

En estas circunstancias, es importante avanzar en aclaraciones conceptuales que permitan guiar la reflexión sobre el lugar que ocupan los deberes de no discriminación en el derecho privado patrimonial y cómo una agenda en contra de la discriminación puede hacerse cargo de ellos. Se trata de un punto difícil porque al mirar los distintos tipos de injusto asociados a discriminación, no es claro en qué medida están constituidos por una ofensa individual, un problema más general de distribución o ambos. Un punto de partida sensato es entender que lo individual y lo colectivo de la prohibición de discriminar no se encuentran en el momento de su aplicación, sino en su instauración. A diferencia de otros deberes jurídicos, el deber de no discriminar requiere de manera crítica una mirada colectiva sobre qué aspectos de nuestra diversidad pueden ser legítimamente considerados al deliberar y qué aspectos, en cambio, constituyen un menoscabo cuando son usados en nuestra contra.

Comprender este punto permite ubicar la relación entre la agenda antidiscriminación y el derecho privado en el contexto de la tensión, más general, que en las sociedades liberales existe entre la persecución de objetivos colectivos y la libertad de los individuos. Una vía para resolver este conflicto es optar porque sean los jueces quienes, aplicando directamente la Constitución caso a caso, resuelvan la forma en que ambos compromisos políticos deben actualizarse. Otra vía es optar por un diseño institucional que, reconociendo el problema que puede darse entre derechos y valores constitucionales, fomente el desarrollo de soluciones diferenciadas que distingan, con anterioridad a cada caso, algunas de las situaciones típicas en que ambos intereses se verán encontrados.

Creemos que la segunda alternativa es mejor que la primera. Construir una política antidiscriminación sólida requiere configurar deberes claros que permitan la actualización del compromiso con la inclusión sin sacrificar ámbitos garantizados de intimidad. Si se respetan estas condiciones, las restricciones a la autonomía que necesariamente traen consigo los deberes de no discriminar pueden ser compatibilizadas con las reglas que el derecho privado contempla para facilitar nuestras relaciones interpersonales.

\section{Bibliografía CITADA}

AleXAnder, Edward (1999). On Liberty.John Stuart Mill. Ontario: Broadview Press. AleXY, Robert (2010). "The Construction of Constitutional Rights". Law \& Ethics of Human Rights, 4. Berlin. 
Atria, Fernando (1997). "Los peligros de la Constitución. La idea de igualdad en la jurisdicción nacional". Cuadernos de Análisis Jurídico, n. ${ }^{\circ}$ 36. Santiago: Universidad Diego Portales.

Atria, Fernando (2004). “¿Existen derechos sociales?”. Discusiones, n. ${ }^{\circ} 4$. Santiago. Atria, Fernando (2016). La forma del derecho. Madrid: Marcial Pons.

AzAR, José Ignacio (2021). "Lo que el derecho civil puede decir de la constitución: una tesis sobre la diferencia", en Departamento de Derecho Privado, FACultad de Derecho Universidad de Chile (coord.). Derecho civil y constitución. Valencia: Tirant lo Blanch.

Barros, Enrique (2001). "Lo público y lo privado en el derecho". Estudios Públicos, vol. 81. Santiago.

Barros, Enrique (2018). "Modernización del derecho chileno de contratos: ¿̇doctrina, jurisprudencia, reforma legal?”, en Claudia BAHAMONDEs et al. (eds.). Estudios de derecho civil XIII. Jornadas Nacionales de Derecho Civil, Pucón, 2017. Santiago: Thomson Reuters.

Barrow, Reginald (1950). Los romanos. (trad.) Margarita Villegas de Róbles. Ciudad de México: Fondo de Cultura Económica.

Bercovitz, Rodrigo (1990). "Principio de igualdad y derecho privado". Anuario de Derecho Civil, vol. 43, n. ${ }^{\circ}$ 2. Madrid.

B’Tselem (2021). "A Regime of Jewish Supremacy from the Jordan River to the 246 Mediterranean Sea: This is Apartheid". Disponible en www.btselem.org/publications/fulltext/202101_this_is_apartheid [fecha de consulta: 28 de mayo de 2021].

Burns, Crosby (2012). “The Costly Business of Discrimination”. Disponible en https://cdn.americanprogress.org/wp-content/uploads/issues/2012/03/pdf/ lgbt_biz_discrimination.pdf?_ga=2.165717566.1067032303.1622492026405705168.1619890374 fecha de consulta: 23 de mayo de 2021].

Cherednychenko, Olha (2007). "Fundamental Rights and Private Law: A Relationship of Subordination or Complementarity?”. Utrecht Law Review, vol. 3, No. 2. Utrecht.

Cohen, G. A. (1977). "Robert Nozick and Wilt Chamberlain: How Patterns Preserve Liberty". Erkenntnis, vol. 11, No. 1. Disponible en www.jstor.org/stable/ 20010531 [fecha de consulta: 28 de mayo de 2021].

Coluins, Hugh (2007). "Utility and Rights in Common Law Reasoning: Rebalancing Private Law Through Constitutionalization”. LSE Legal Studies Working Paper, No. 6/2007. London.

Collins, Hugh (2013). "The Vanishing Freedom to Choose a Contractual Partner". Law and Contemporary Problems, vol. 76, No. 2. Durham.

Collins, Hugh \& Tarunabh Khaitan (2018). "Indirect Discrimination Law: Controversies and Critical Questions", in Hugh Collins \& Tarunabh KHAitan (eds.). Foundations of Indirect Discrimination Law. Oxford: Hart Publishing.

Comisión Inter-Americana de Derechos Humanos (2019). Equality and Nondiscrimination. Inter-American Standards. Disponible en www.oas.org/en/ 
iachr/reports/pdfs/Compendium-EqualityNonDiscrimination.pdf [fecha de consulta: 28 de mayo de 2021].

Comité Especial de Naciones Unidas sobre las Políticas de Apartheid del Gobierno de la República de SudÁfrica (1964). "Report of the Special Committee on the Policies of Apartheid of the Government of the Republic of South Africa". Disponible en https://digitallibrary.un.org/record/538171? ?n=es [fecha de consulta: 31 de mayo de 2021].

Corte Interamericana de Derechos Humanos (2019). Cuadernillo de jurisprudencia de la corte interamericana de derechos humanos $n^{0}$ 14: igualdad y no discriminación. Disponible en www.corteidh.or.cr/sitios/libros/todos/docs/cuadernillo14.pdf [fecha de consulta: 28 de mayo de 2021].

Dabin, Jean (1955). El derecho subjetivo. (trad.). F. J. Osset. Madrid: Editorial Revista de Derecho Privado.

Dagan, Hanoch \& Benjamin Zipursky (2020). "The Distinction Between Public Law and Private Law", in Hanoch Dagan \& Benjamin Zipursky (eds.). Research Handbook on Private Law Theory. Cheltenham: Edward Elgar Publishing.

DiAz, Iván (2013). "Ley chilena contra la discriminación. Una evaluación desde los derechos internacional y constitucional". Revista Chilena de Derecho, vol. 40, n. ${ }^{\circ}$ 2. Santiago.

DíAz de VALdés, José Manuel (2013). “¿Es la ley Zamudio verdaderamente una ley general antidiscriminación?”. Actualidad Jurídica, n. ${ }^{\circ}$ 28. Santiago.

DíAz de VaLdés, José Manuel (2014). "La prohibición de una discriminación arbitraria entre privados". Revista de Derecho de la Pontificia Universidad Católica de Valparaíso, vol. 42, n. ${ }^{\circ}$. Valparaíso.

DíAZ DE VALDÉs, José Manuel (2017). “Cuatro años de la ley Zamudio: análisis crítico de su jurisprudencia”. Estudios Constitucionales, vol. 15, n. ${ }^{\circ}$ 2. Santiago.

DíAz de VAldés, José Manuel (2018). Igualdad constitucional y no discriminación. Santiago: Tirant Lo Blanch.

Dorfman, Avihay (2020). “The Limited Case for Discrimination's Legality”. Law and Contemporary Problems, vol. 83, No. 2. Durham.

Dorfman, Avihay (2018). "Private Law Exceptionalism? Part II: A Basic Difficulty with the Argument from Formal Equality". Canadian Journal of Law \& Jurisprudence, vol. 31, No. 1. Disponible en https://papers.ssrn.com/sol3/papers. cfm?abstract_id=3034145 [fecha de consulta: 28 de mayo de 2021].

Dworkin, Ronald (1977). "Why Bakke Has No Case". Disponible en www.nybooks. com/articles/1977/11/10/why-bakke-has-no-case/\#: :text=On\%20October $\% 2012 \% 20$ the $\% 20$ Supreme,the $\% 20$ University $\% 20$ of $\% 20$ California $\% 20$ v.\&text $=$ Bakke $\% 20$ sued $\% 2 \mathrm{C} \% 20$ arguing $\% 20$ that $\% 20$ the, medical $\% 20$ school\%20to\%20admit\%20him [fecha de consulta: 28 de mayo de 2021].

Dworkin, Ronald (1986). Law's Empire. Cambridge, Massachusetts: Harvard University Press.

Dworkin, Ronald (2000). Sovereign Virtue: The Theory and Practice of Equality. Cambridge, Massachusetts: Harvard University Press. 
EndicotT, Timothy (2013). "Proportionality and Incommensurability". University of Oxford Legal Research Paper Series, No. 40/2012. Oxford.

Feinberg, Joel (1987). The Moral Limits of the Criminal Law New York: Oxford University Press. Vol. 1: Harm to Others.

Fermandois, Arturo y Teresita Chubretovic (2016). "El recurso de protección en asuntos ambientales: criterios para su procedencia postinstitucionalidad ambiental (2010-2015)”. Revista Chilena de Derecho, vol. 43, n. ${ }^{\circ}$ 1. Santiago.

Fiss, Owen (1976). "Groups and the Equal Protection Clause". Philosophy \& Public Affairs, vol. 5, No. 2. Disponible en www.jstor.org/stable/2264871 [fecha de consulta: 28 de mayo de 2021].

FORAN, Michael (2019). "Discrimination as an Individual Wrong". Oxford Journal of Legal Studies, vol. 4, No. 4. Oxford.

Fredman, Sandra (2011). Discrimination Law. Oxford: Oxford University Press.

Fredman, Sandra (2018). "Direct and Indirect Discrimination: Is There Still a Divide?", in Hugh Collins \& Tarunabh KHAitan (eds.). Foundations of Indirect Discrimination Law. Oxford: Hart Publishing.

GARDNER, John (1989). "Liberals and Unlawful Discrimination". Oxford Journal of Legal Studies, vol. 9, No. 1. Oxford.

Gardner, John (2014). "Some Rule-of-Law Anxieties about Strict Liability in Private Law", in Lisa M. Austin \& Dennis Klimchuk (eds.). Private Law and the Rule of Law. Oxford: Oxford University Press.

Gardner, John (2017). "Dagan and Dorfman on the Value of Private Law". Columbia Law Review, vol. 117. New York.

Gardner, John (2018). "Discrimination: The Good, the Bad, and the Wrongful". Proceedings of the Aristotelian Society, vol. 118, No. 1. London.

Hart, H. L. A. (1968). "Lega Responsibility and Excuses", in H. L. A. Hart, Punishment and Responsibility. Oxford: Oxford University Press.

Havelková, Barbara \& Mathias Möschel (2020). Anti-Discrimination Law in Civil Law Jurisdictions. Oxford: Oxford University Press.

HaYek, Friedrich (2006). Derecho, legislación y libertad: una nueva formulación de los principios liberales de la justicia y de la economía política. (trad.) Luis REIG. Madrid: Unión Editorial.

Hellman, Deborah (2008). When Is Discrimination Wrong?Harvard: Harvard University Press.

Hellman, Deborah (2013). "Equality and Unconstitutional Discrimination", in Deborah Hellman \& Sophia Moreau (eds.). Philosophical Foundations of Discrimination Law. Oxford: Oxford University Press.

Hellman, Deborah \& Sophia Moreau (2014). Philosophical Foundations of Discrimination Law. Oxford: Oxford University Press.

Holmes, Elisa (2005). “Anti-Discrimination Rights without Equality”. The Modern Law Review, vol. 68, No. 2. London. 
Human Rights Watch (2021). "A Threshold Crossed Israeli Authorities and the Crimes of Apartheid and Persecution". Disponible en www.hrw.org/report/2021/04/27/threshold-crossed/israeli-authorities-and-crimes-apartheidand-persecution [fecha de consulta: 28 de mayo de 2021].

JANA, Andrés (2021). "La eficacia horizontal de los derechos fundamentales", en Departamento de Derecho Privado, Facultad de Derecho Universidad DE ChILE (coord.). Derecho civil y constitución. Valencia: Tirant lo Blanch.

Jana, Andrés y Juan Carlos Marín (1996). Recurso de protección y contratos. Santiago: Editorial Jurídica de Chile.

Josserand, Louis (1939). De l'esprit des droits et de leur relativité: théorie dite de l'abus des droits. Paris: Dalloz.

Kamm, Frances (2002). "Rights", in Jules Coleman \& Scott J. Shapiro (eds.). The Oxford Handbook of Jurisprudence and Philosophy of Law. Oxford: Oxford University Press.

KhaITAn, Tarunabh (2015). A Theory of Discrimination Law. Oxford: Oxford University Press.

Khaitan, Tarunabh \& Sandy Steel (2018). "Wrongs, Group Disadvantage and the Legitimacy of Indirect Discrimination Law", in Hugh Coluins \& Tarunabh Khaitan (eds.). Foundations of Indirect Discrimination Law. Oxford: Hart Publishing.

Kumm, Mattias (2006). "Who is Afraid of the Total Constitution? Constitutional Rights as Principles and the Constitutionalization of Private Law". German Law Journal, vol. 7, No. 4. Disponible en www.cambridge.org/core/journals/germanlaw-journal/article/who-is-afraid-of-the-total-constitution-constitutional-rightsas-principles-and-the-constitutionalization-of-private-law/EBC569B92946B25C660EF539788A109A [fecha de consulta: 28 de mayo de 2021].

Landes, William \& Robert Posner (1987). The Economic Structure of Tort Law. Cambridge: Harvard University Press.

Lippert-Rasmussen, Kasper (2013). Born Free and Equal?: A Philosophical Inquiry Into the Nature of Discrimination. Oxford: Oxford University Press.

McWhorter, Ladelle (2004). "Sex, Race, and Biopower: A Foucauldian Genealogy”. Hypatia, vol. 19, No. 3. New York.

McWilliams, Carey (1945). "Race Discrimination and the Law". Science \& Society, vol. 9, No. 1. New York.

Monahan, John, Laurens Walker \& Gregory Mitchell (2008). "Contextual Evidence of Gender Discrimination: The Ascendance of 'Social Frameworks'". Virginia Law Review, vol. 94, No. 7. Charlottesville.

Moreau, Sophia (2010). "What Is Discrimination?". Philosophy \& Public Affairs, vol. 38, No. 2. Disponible en https://onlinelibrary.wiley.com/doi/abs/10.1111/ j.1088-4963.2010.01181.x [fecha de consulta: 28 de mayo de 2021].

Nozick, Robert (1974). Anarchy, State and Utopía. New York: Basic Books.

PashuKanis, Evgeni (1976). Teoría general del derecho y marxismo. (trad.) Virgilio ZAPATERO. Barcelona: Editorial Labor. 
PNUD (2017). Desiguales. Orígenes, cambios y desafios de la brecha social en Chile. Santiago: Uqbar Editores.

Posner, Richard (1979). "The Bakke Case and the Future of 'Affirmative Action"”. California Law Review, 67. Berkeley.

Rawls, John (1955). "Two Concepts of Rules”. The Philosophical Review, vol. 64, No. 1. Durham.

Ripstein, Arthur (2000). “Three Duties to Rescue: Moral, Civil, and Criminal”. Law and Philosophy. vol. 19, No. 6. Disponible en https://doi.org/10.2307/3505073 [fecha de consulta: 28 de mayo de 2021].

SAlaH, María Agnes (2019). "Tres visiones de la igualdad para el derecho sucesorio", en Esteban Pereira (ed.). Fundamentos filosóficos del derecho civil chileno. Santiago: Rubicón.

SEINER, Joseph (2006). "Disentangling Disparate Impact and Disparate Treatment: Adapting the Canadian Approach". Yale Law \& Policy Revierw, vol. 25, No. 1. New Haven.

Somek, Alexander (2011). Engineering Equality: An Essay on European Anti-Discrimination Law. Oxford: Oxford University Press.

Soto, Claudia (2016). "Nuevo caso de discriminación en edificio: reglamento prohíbe uso de piscina para nanas y sus hijos". Disponible en www.latercera.com/ noticia/nuevo-caso-discriminacion-edificio-reglamento-prohibe-uso-piscinananas-hijos/ fecha de consulta: 23 de mayo de 2021].

Supiot, Alain (2012). Homo juridicus. Ensayo sobre la función antropológica del derecho. (trad.) Silvio Mattoni. Buenos Aires: Siglo Veintiuno Editores.

TAPIA, Mauricio (2007). "Constitucionalización del derecho de familia(s) el caso chileno: las retóricas declaraciones constitucionales frente a la lenta evolución social". Revista Chilena de Derecho Privado, n. ${ }^{\circ}$ 8. Santiago.

The Economist (2021). "White Americans are beginning to realise that they too belong to a race". Special report May 22, 2021. Disponible en www.economist.com/ special-report/2021/05/14/the-souls-of-white-folk fecha de consulta: 28 de mayo de 2021].

Tishkoff, Sarah \& Kenneth Kidd (2004). "Implications of Biogeography of $\mathrm{Hu}$ man Populations for 'Race' and Medicine". Nature Genetics 36. London.

Tsakyrakis, Stavros (2009). "Proportionality: An assault on human rights?". International Journal of Constitutional Law, vol. 7, No. 3. Oxford.

URRUTIA, Ignacio (2004). "Recurso de protección en contra de actos administrativos dictados en el marco del sistema de evaluación de impacto ambiental”, en LeXIS NeXis (ed.). Prevención y solución de conflictos ambientales: vías administrativas, jurisdiccionales y alternativas. Actas de las $2^{\text {as }}$ Jornadas Nacionales de Derecho Ambiental, Facultad de Derecho, Universidad de Chile. Santiago: LexisNexis.

Von Savigny, Friedrich Carl (1979). System of the Modern Roman Law, II. (trad.) William Holloway. Connecticut: Hyperion Press. 
WALDRON, Jeremy (1985). "Indirect Discrimination", in Stephen Guest \& Alan Milne (eds.). Equality and Discrimination: Essays in Freedom and Justice. Stuttgart: Steiner.

Worstall, Tim (2016). "Business Gender Diversity Solved: More Women Means More Profits". Disponible en www.forbes.com/sites/timworstall/2016/02/10/business-gender-diversity-solved-more-women-means-moreprofits/?sh=1c31a263170f fecha de consulta: 23 de mayo de 2021].

Young, Alison (2011). "Mapping Horizontal Effect", in David Hoffman (ed.). The Impact of the UK Human Rights Act on Private Law. Cambridge: Cambridge University Press.

\section{Jurisprudencia citada}

A., C. y B. con Reino Unido (1985): Tribunal Europeo de Derechos Humanos, 28 de mayo de $1985, n$. ${ }^{\text {os }} 9214 / 80 ; 9473 / 81$ y $9474 / 81$.

A. y niñas con Chile (2012): Corte Interamericana de Derechos Humanos, 24 de febrero de 2012, Serie C n. 239.

A. M. y otros ("Fecundación in vitro") con Costa Rica (2012): Corte Interamericana de Derechos Humanos, 28 de noviembre de 2012, Serie C n. 257.

AP. and RP. v. Andorra (2006): Tribunal Europeo de Derechos Humanos, 13 de julio de 2006, 42 EHRR 25.

B. v. Board of Education (1954): Supreme Court of the United States, May 17, 1954, 347 U.S. 483 (1954).

C. con Corporación Iglesia Adventista del Séptimo Día (2020: Corte Suprema, 17 de noviembre de 2020, rol n. ${ }^{\circ}$ 127174-2020. Como uy donde se ubica.

Centrum voor gelijkheid v. F. (2008): Corte Europea de Justicia, 10 de julio de 2008, ECJ C-54/07.

Chipre con Turquía (2001): Tribunal Europeo de Derechos Humanos, 10 de mayo de 2001, n. ${ }^{\circ} 25781 / 94$.

Comunidad Indígena Xákmok Kásek con Paraguay (2010): Corte Interamericana de Derechos Humanos, 24 de agosto de 2010, serie C n. 214.

E. con Perú (2014): Corte Interamericana de Derechos Humanos, 20 de noviembre de 2014, Serie C n. ${ }^{\circ} 289$.

G. v. Duke Power Company (1971): Supreme Court of the United States, March 8, 1971, 401 US 424 (1971).

G. y otros con Ecuador (2015): Corte Interamericana de Derechos Humanos, 1 de septiembre de 2015, Serie C n. 298.

G. y otros (Radio Caracas Televisión) con Venezuela (2015): Corte Interamericana de Derechos Humanos, 22 de junio de 2015, Serie C n. 293.

HM Chief Inspector v. Interim Executive of Al Hijrah School (2018): England and Wales Court of Appeal (Civil Division), October 1, 2017, [2017] EWCA Civ 1426. 
I. con Austria (1989): Tribunal Europeo de Derechos Humanos, 28 de octubre de 1987, 8695/79.

L. v. Ashers Baking Company Ltd. and others (2018): Supreme Court of the United Kingdom, October 10, de 2018, UKSC 49.

Masterpiece Cakeshop, Ltd. v. Colorado Civil Rights Commission et al. (2018): Supreme Court of the United States, June 4, 2018, 138 S. Ct. 1719, 1724 (2018).

N. y otros con Bulgaria (2005): Tribunal Europeo de Derechos Humanos, 6 de julio de 2005, n. ${ }^{\text {os }} 43577 / 98$ y $43579 / 98$.

N. y otros (dirigentes, miembros y activista del Pueblo Indígena Mapuche) con Chile (2014): Corte Interamericana de Derechos Humanos, 29 de mayo de 2014, Serie C n. 279.

N. y otros con República Dominicana (2012): Corte Interamericana de Derechos Humanos, 24 de octubre de 2012, Serie C n. 251.

PB. and HB. v. H. and P. (2013): Supreme Court of the United Kingdom, November 27, 2013, SCUK 73.

Regents of the University of California v. B. (1978): Supreme Court of the United States, June 28, 1978, 438 U.S. 265 (1978).

Servicio Nacional del Consumidor con Centro de Salud y Recreación Gunter Mund y Compañía Limitada (1993): Corte de Apelaciones de Santiago, 7 de abril de 1993, rol n. ${ }^{\circ} 486-1993$.

252 U. con F. G. M. y Compañía Limitada (2019): Corte Suprema, 10 de octubre de 2019, rol n. ${ }^{\circ} 8034-2018$.

V. con Servicio de Registro Civil e Identificación (2020): Requerimiento de inaplicabilidad respecto del artículo 12 , inciso final, de la ley $\mathrm{N}^{\circ} 20.830$ y de la frase "siempre que se trate de la unión entre un hombre y una mujer" contenida en el artículo 80, inciso primero, de la ley $\mathrm{N}^{\circ}$ 19.947: Tribunal Constitucional, 4 de junio de 2020, rol n. ${ }^{\circ}$ 7774-2019.

\section{Normas citadas}

Código del Trabajo de Chile, 1987.

Constitución Política de la República de Chile, 1980.

Ley n. ${ }^{\circ}$ 19496, sobre protección de los derechos de los consumidores. Diario Oficial de la República de Chile, Santiago, 7 de marzo de 1997.

Ley n. ${ }^{\circ} 20609$, sobre el establecimiento de medidas contra la discriminación arbitraria. Diario Oficial de la República de Chile, Santiago, 24 de julio de 2012.

SigLAS Y ABREVIATURAS

al. alii (otros)

art. artículo 
arts. artículos

coord. coordinador

eds. editores

https Hypertext Transfer Protocol Secure

n. ${ }^{0}$ número

n. ${ }^{\text {os }}$ números

op. cit. opere citato (obra citada)

p. página

PNUD Programadelas Naciones Unidas para el Desarrollo

pp. páginas

ss. siguientes

Trad. traducción

v. versus

vol. volumen

www World Wide Web 